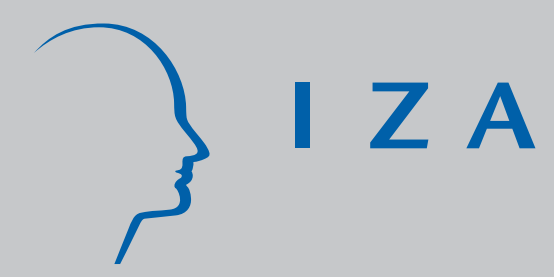

IZA DP No. 925

Employment Effects of Dispersal Policies on Refugee Immigrants, Part II: Empirical Evidence

Anna Piil Damm

Michael Rosholm

November 2003 


\title{
Employment Effects of Dispersal Policies on Refugee Immigrants, Part II: Empirical Evidence
}

\author{
Anna Piil Damm \\ CIM, Aarhus School of Business \\ Michael Rosholm \\ Institute of Local Government Studies (AKF), \\ University of Aarhus and IZA Bonn
}

\section{Discussion Paper No. 925 \\ November 2003}

\author{
IZA \\ P.O. Box 7240 \\ D-53072 Bonn \\ Germany \\ Tel.: +49-228-3894-0 \\ Fax: +49-228-3894-210 \\ Email: iza@iza.org
}

\begin{abstract}
This Discussion Paper is issued within the framework of IZA's research area Mobility and Flexibility of Labor. Any opinions expressed here are those of the author(s) and not those of the institute. Research disseminated by IZA may include views on policy, but the institute itself takes no institutional policy positions.
\end{abstract}

The Institute for the Study of Labor (IZA) in Bonn is a local and virtual international research center and a place of communication between science, politics and business. IZA is an independent, nonprofit limited liability company (Gesellschaft mit beschränkter Haftung) supported by Deutsche Post World Net. The center is associated with the University of Bonn and offers a stimulating research environment through its research networks, research support, and visitors and doctoral programs. IZA engages in (i) original and internationally competitive research in all fields of labor economics, (ii) development of policy concepts, and (iii) dissemination of research results and concepts to the interested public. The current research program deals with (1) mobility and flexibility of labor, (2) internationalization of labor markets, (3) welfare state and labor market, (4) labor markets in transition countries, (5) the future of labor, (6) evaluation of labor market policies and projects and (7) general labor economics.

IZA Discussion Papers often represent preliminary work and are circulated to encourage discussion. Citation of such a paper should account for its provisional character. A revised version may be available on the IZA website (www.iza.org) or directly from the author. 


\title{
ABSTRACT
}

\section{Employment Effects of Dispersal Policies on Refugee Immigrants, Part II: Empirical Evidence*}

\begin{abstract}
How do dispersal policies affect labour market integration of refugee immigrants subjected to such policy? To investigate this, we estimate the effects of location characteristics and the average effect of geographical mobility on the hazard rate into first job of refugee immigrants subjected to the Danish Dispersal Policy 1986-1998. We correct for selection into relocation to another municipality by joint estimation of the duration of the first non-employment spell and time until relocation. The main estimation results are as follows: First, the hazard rate into first job is increasing in the concentration of fellow countrymen and decreasing in the regional unemployment rate, the size of the local population and the percentage of immigrants in the local population. The two latter findings support dispersal policies. The two former findings emphasize that refugees should be dispersed in big clusters of refugees of the same ethnic origin across regions with low unemployment. Second, on average, geographical mobility had large, positive effects on the job finding rate, suggesting that either relocations were carried out to improve employment prospects, or they were carried out to improve place utility and thereby lower the reservation wage. Hence, restrictions on placed refugees' subsequent migration (or on their initial choice of location) would hamper labour market integration.
\end{abstract}

JEL Classification: J64, J61, J15

Keywords: dispersal policies, employment effects, geographical mobility, refugee immigrants

Corresponding author:

Michael Rosholm

Department of Economics

University of Aarhus

Building 326

8000 Aarhus C

Denmark

Tel.: +4589421559

Fax: +45861363 34

Email: mrosholm@econ.au.dk

\footnotetext{
* We thank participants at the JESS Seminar at ISER, University of Essex, in February 2003 and participants at the CIM workshop in Rørvig in May 2003, notably Peter Jensen, Aarhus School of Business, for useful comments. In addition, we thank the Institute of Local Government Studies for facilitating our access to the Danish longitudinal administrative register data set on the immigrant population.
} 


\section{Introduction}

Numerous European countries carry out policies affecting the location of refugees, specifically by locating new refugees away from immigrant-dense cities and regions. Such dispersal policies for refugees are carried out in Germany, the Netherlands, UK, Norway, Denmark, and to some extent also in Sweden, for two reasons. First, residential concentration and segregation of immigrants is commonly believed to hamper the integration process of immigrants by slowing down the acquisition of country-specific human capital, such as language skills and knowledge about the host country (the integration motive). Second, cities that receive a large proportion of the immigrant inflow often consider this a financial and social burden since new immigrants tend to have a low labour market attachment initially (the public finance motive).

Those criticising active dispersal policies claim, however, that not allowing people to choose location for themselves will lead to higher secondary migration rates, i.e. relocations within the host country, which will undo some of the intended results of the policy. Evidence for Norway (Djuve and Kavli 2000), Sweden (Åslund 2001) and Denmark (Hummelgaard et al. 1995, Damm 2003b) shows very high relocation rates out of small municipalities toward the larger towns and cities during the first two-three years after the initial settlement and supports this hypothesis. ${ }^{1}$ Furthermore, Edin et al. (2001) find evidence that refugee immigrants dispersed according to the 'Whole of Sweden Strategy' experienced long-run losses (measured in terms

\footnotetext{
${ }^{1} 36 \%$ of the 20,000 refugee immigrants who were located away from immigrant-dense areas in Norway during 1994-96 had moved away from the municipality of assignment at the end of 1999. The general relocation pattern was that the further away from the metropolitan area in South Norway placement had taken place, the higher the relocation rates for leaving the region. As much as $57 \%$ of the refugee immigrants located in the Northern part of Norway left the region. The main part of the movers moved to towns or cities (Djuve and Kavli 2000).

Åslund (2001) finds that $37.6 \%$ of the refugee immigrants who were located according to the Whole of Sweden Strategy during 1987-1989 had relocated to another municipality within four years after the initial settlement. In addition, he finds that refugees tend to leave small municipalities and are attracted to large municipalities.

In line with the relocation pattern found for refugee immigrants subjected to a settlement policy in Norway or Sweden, Damm (2003b) finds that 33\% of 48,000 refugee immigrants aged 18-66 and placed during 1986-1998 relocated to another municipality on the average after 2 years. For refugee immigrants placed in small municipalities the relocation rate was as high as $44 \%$.
} 
of earnings, idleness and welfare receipt) due to the dispersal policy. They also stress that the secondary migration pattern actually lowers the potential long-run losses due to the policy because of the tendency for refugees to migrate out of areas in which they have bad employment prospects. Specifically, their estimates suggest that the probability of being idle eight years after immigration would have been 20 percentage points higher if refugees had stayed in the assigned municipalities rather than moved away. However, for Denmark it is still an unresolved issue whether refugee immigrants experience losses due to the Danish Dispersal Policy and whether the subsequent relocations of refugee immigrants lower the potential losses of the policy or undo some of potential benefits of the policy.

This study is an empirical investigation of the employment effects of the Danish Dispersal Policy for the refugee immigrants subjected to the policy. The purpose of the study is to answer two main questions. First, whether refugee immigrants experience a loss in terms of employment due to the dispersal policy. Second, whether geographical mobility of jobless refugee immigrants helps them gain economic independence. These questions are addressed by investigation of whether and how the initial random location of refugee immigrants affects their job finding rates and investigation of whether relocation to another municipality of residence helps jobless immigrants find their first job. In particular, we estimate the effect of initial location as well as of first relocation and further relocations on the transition rate from nonemployment to the first job controlling for demographic and socio-economic characteristics of the individual. We argue that the total effect of relocation is the sum of two effects: an effect due to differences between observed characteristics of the destination municipality and those of the former municipality of residence and an effect due to unobservables. We correct for selection into relocation by modelling the relocation process explicitly, using both individual and municipal characteristics as explanatory variables, an aspect which is found to be important in Damm (2003b). This implies that we jointly estimate the duration of the first non-employment spell and time until relocation.

The analysis is based on a longitudinal register data set covering all immigrants in Denmark. The data contain information on municipality of residence and date of residential mobility into another municipality which allows us to construct residential spells for each individual. In addition, we have made use of the labour market spells of immigrants constructed by the Institute of Local Government Studies. Finally, we use municipality time series 
data to construct location characteristics.

The main estimation results are as follows. First, we find that residence in a small or medium-sized municipality further characterised by low regional unemployment, a small immigrant population and a high concentration of fellow countrymen increases the hazard rate of exit to the first job for the refugees substantially. Second, on average, the employment prospects - measured in terms of observable characteristics of the municipality of residence - deteriorate when non-employed initially placed refugees carry out a crossmunicipal move. However, the average treatment effect of cross-municipal moves due to unobservables on the exit rate to the first job is large and positive and dominates the negative effect of relocation due to deterioration of observable location characteristics.

The remainder of the paper is structured as follows. The Danish Dispersal Policy on refugee immigrants is described in Section 2. In Section 3, we present our hypotheses concerning the relationship between initial settlement, geographical mobility and finding employment for non-employed refugee immigrants. A description of the data is given in Section 4. In Section 5, the econometric model for estimation is set up. Section 6 explains and discusses the estimation results. This section is followed by an overview of the sensitivity analyses results. The final section, Section 8, concludes.

\section{The Danish Dispersal Policy on refugee im- migrants}

In the 1980s, the majority of refugees granted asylum in Denmark wanted to settle in the capital or in one of the larger towns. The Danish Refugee Council (Dansk Flygtningehjælp) was responsible for helping refugees find permanent housing. Since a rising number of refugees were granted asylum in Denmark in 1984 the Danish Refugee Council (DRC) was no longer able to provide all refugees with housing in one of their preferred cities. DRC therefore had to start providing some refugees with housing in medium-sized towns. As the number of refugees granted asylum continued to rise in 1985 and 1986, it became increasingly difficult to find permanent housing for refugees in the typically preferred cities, which led the government and politicians in general to urge DRC to disperse refugees over all 14 Danish counties and the two county municipalities. DRC reformed its dispersal policy according to the 
political wishes.

1986 marks the start of the first Danish active dispersal policy which was in force until 1999 and was carried out by DRC. In 1986, 182 out of a total of 275 municipalities in Denmark received refugees who during an introductory period of 18 months participated in Danish language courses while receiving social benefits. In 1999, a more strict dispersal policy came into force which aimed at promoting better integration of refugees by means of further geographical dispersal ${ }^{2}$ and an extended introduction programme ${ }^{3}$ supplied by the municipality in which the refugee lives (law no. 474 passed the 1st of July 1998).

In the following, only the first of the two active dispersal policies will be described, since register data are currently available only for the years of the first active dispersal policy.

After the reform in 1986, all refugees, apart from reunification immigrants, were subjected to the active dispersal policy unless they could find a place of living themselves. During the period 1986-1994, approximately $91 \%$ of the refugees were provided with or assisted in finding permanent housing by DRC under the terms of the dispersal policy. ${ }^{4}$ Internal administrative statistics of DRC for 1995-1998 indicate that from 1995-1997 approximately $89 \%$ of new refugees were provided with permanent housing by DRC or - as a new feature of the dispersal policy - by a local government if it had wished to take over the responsibility for new refugees in the municipality from DRC.

DRC's assignment policy aimed at promoting an equal distribution of refugees in proportion to the population in each county. ${ }^{5}$ At the county level,

\footnotetext{
${ }^{2}$ All municipalities now have to take part in the integration process of refugees. When granted asylum newly arrived refugees are distributed between the municipalities in such a way that municipalities with a low percentage of ethnic minorities receive a large share of newly arrived refugees whereas municipalities with a high percentage of ethnic minorities receive a low share of or no new refugees. The municipalities are now responsible for providing refugees with appropriate housing.

${ }^{3}$ The introduction programme consists of a Danish course, a course about the Danish society and job-oriented training. The programme has been extended from 18 months to three years.

${ }^{4}$ This number has been calculated as the total number of refugees who found permanent housing in the period 1986-1994 with assistance of the Danish Refugee Council $(37,121)$ divided by the sum of the total number of refugees having received a permit to stay in the period $(38,598)$ and the number of refugees in temporary housing at the beginning of 1986 (3882) minus the number of refugees still in temporary housing at the end of 1994 (1710) (Annual Reports of the Danish Refugee Council 1986-1994).

${ }^{5}$ Denmark is divided into 14 county council districts.
} 
DRC aimed at the attainment of an equal distribution of refugees over a number of years among those municipalities, which had the necessary facilities for integration such as dwellings, educational institutions and employment opportunities and in which refugees had the opportunity of socialising with compatriots. When deciding to which county a refugee should be assigned, location wishes of the refugee, if any, should be taken into account. In practice, these dispersal criteria implied that new refugees were provided with permanent housing in the metropolitan area, the larger cities and mediumsized towns and to a lesser extent in the rural districts (Ministry of Internal Affairs 1996).

The refugees were urged to stay in the assigned municipality during the entire introductory period. However, there were no restrictions against relocating. Refugees could move away from their initial municipality any time, in so far as they could find housing elsewhere on their own. In addition to moving costs, such a relocation involved potential costs in form of having to wait before being admitted into a new language course and, in case of small children, waiting for their admittance into a new kindergarten. Receipt of welfare was not conditional on residing in the assigned municipality.

Empirical evidence shows that the assignment policy did, at least in the short run, influence the location patterns of refugees. By 1993, $71 \%$ of the non-western immigrants other than refugees lived in the metropolitan area whereas only $33 \%$ of refugee immigrants and $26 \%$ of the population as such lived here. $24 \%$ of non-western immigrants other than refugees lived in towns outside the metropolitan area whereas $56 \%$ of refugee immigrants, and $59 \%$ of the population as such lived here. Finally, only $5 \%$ of the non-western immigrants lived in rural districts against almost $12 \%$ of the refugee immigrants and $15 \%$ of the population as such (Danish Refugee Council 1993).

In 1995, Denmark granted asylum to an unusually large number of refugees due to large inflows of refugees from Bosnia-Herzegovina. Due to acute housing problems and the temporary character of the permit to stay, a special introduction programme was developed for refugees from Bosnia-Herzegovina (see Ministry of Internal Affairs 1995). Contrary to the dispersal policy under the ordinary introduction programme, the special introduction programme included settlement in rural districts, thereby fully ignoring whether a municipality had suitable characteristics for reception or not. Instead, the availability of housing became the decisive factor.

In Damm (2003a), it is argued that the way in which the dispersal policy was implemented gave rise to a random initial distribution of the refugee 
immigrants who were provided with or assisted in finding permanent housing by DRC, conditional on seven characteristics of the individual: marital status, health (in need of special medical or psychological treatment), special educational needs, the location of close family and friends, nationality, year of immigration (it became increasingly difficult for DRC to find housing in the larger and medium-sized towns) as well as firm resolution to live in a certain area of Denmark/reluctance to accept assignment to a non-preferred county. These governing factors suggest that non-single refugees in need of special treatment and education and refugees with close family in Denmark near whom they were determined to live and who arrived early in the observation period were most likely to realise their preferred settlement option. Three of these characteristics are observed in Danish administrative register data (described in Section 4): family status as measured by marital status and number of children, nationality and year of immigration. Moreover, in Damm (2003a) it is argued that age and nationality may be decent proxies for educational needs and that nationality and size of the ethnic stock may be decent proxies for whether the individual had close family and friends in Denmark at the time of arrival. In contrast, no decent proxy for need of special medical or psychological treatment is present in the registers. Finally, the last-mentioned characteristic is probably of minor importance: the combination of generally high settlement rates and generally low reassignment rates indicates that only a small fraction of the refugees have insisted on living in a particular area of Denmark.

In the empirical analysis carried out later in this paper, we thus condition on five out of the six characteristics of the individual which may have influenced the initial settlement of an individual: marital status, number of children, nationality, year of immigration, age and size of the ethnic stock which allows us to treat the initial location of a refugee immigrant as otherwise exogenous.

\section{Hypotheses}

A jobless individual may move to another municipality for various reasons including job search. Moreover, those deciding to move in order to improve their job finding probability may not be randomly selected among the group of refugee immigrants. Rather, they are likely to be those with e.g. most motivation. Failure to take such potential endogeneity of the location of 
residence into account when estimating the effect of relocation on the job finding rate may result in a biased estimate of the effect.

Various studies of new immigrants' location choice exist which have found some empirical evidence supporting the hypothesis of the endogeneity of location choice. Studies for the US (Bartel 1989, Zavodny 1997, Borjas 1999, Jaeger 2000, Bauer et al. 2002), Sweden (Åslund 2001) and Denmark (Damm 2003b) show that new immigrants tend to settle in large cities where other ethnic minorities live. Employment and income prospects also seem to influence the settlement considerations - at least for most refugee groups (Jaeger 2000, Åslund 2001). Contrasting evidence has been found, however, for whether or not welfare seeking is important for immigrants' settlement decision (Zavodny 1998, Borjas 1999, Åslund 2001).

According to our knowledge, no theoretical models exist concerning optimal job and residential location search of refugee immigrants. However, models exist which explain job and residential search behaviour for unemployed and employed workers in general. The most general among these is the model by Van Ommeren et al. (1997, 2000).

The point of departure of the Van Ommeren et al. (1997, 2000) model is that individuals maximise life-time utility by moving through different labour market and residential location states, while taking into consideration that moving from one state to another is costly. Optimal strategies are derived both for employed and non-employed individuals giving rise to four reservation value strategies, for job moves/acceptance and residential relocation for employed and unemployed individuals, respectively. One of their main conclusions based on the search model is that the reservation wages for employed and non-employed workers depend on labour market characteristics as well as housing market characteristics. That is also the case for the reservation place utility. ${ }^{6}$ According to their model, job and residential search behaviour of an unemployed person are described by transition rates which are the product of an offer arrival rate and the conditional probability of accepting an offer. Comparative static results for non-employed individuals show that the higher the current place utility, the higher are the reservation wage and reservation place utility. The interpretation of the first result is that individuals with high current place utility are more attached to their present

\footnotetext{
${ }^{6}$ The concept of 'place utility' was developed by Wolpert who defined it as "a positive or negative quantity, expressing respectively the individual's satisfaction or dissatisfaction with respect to that place" (Wolpert 1965, p. 162).
} 
location of residence and therefore less willing to accept a job which induces a residential move. The interpretation of the second result is straightforward, that the higher your current place utility is, the better a residence offer must be for you to accept it. In consequence, the model by Van Ommeren et al. (1997, 2000) predicts that the job-finding rate and housing mobility rate of non-employed individuals are both decreasing in current place utility.

The model by Van Ommeren et al. (1997, 2000) constitutes a good description of the interaction between job and residential mobility for native born individuals. New immigrants, however, may initially differ from individuals in the workforce by lack of information necessary for conducting e.g. job search outside a defined local labour market. Furthermore, dispersal policies aim at labour market integration of refugee immigrants within the region of assignment. For these two reasons, the distinction between the local labour market and the national labour market is important for analysis of employment effects of dispersal policies on refugee immigrants. The model by Van Ommeren et al. (1997, 2000) does not distinguish between local and national job search. The optimal search strategies for refugee immigrants may therefore be different from those described in Van Ommeren et al. (1997, 2000). To fill this theoretical gap, in a companion paper, Damm and Rosholm (2003), we formulate a simultaneous job and residence search model for refugee immigrants who are initially subject to a dispersal policy.

In our model, refugee immigrants begin searching for a job and a new residence simultaneously at the time at which they are granted asylum. The model we present is set up to analyse implications of dispersal policies, according to which new refugee immigrants are settled in a specific residential location away from immigrant-dense areas by the authorities.

The relationship between job and residential location search behaviour is described from a search-theoretical perspective. The point of departure is that initially non-employed individuals face a set of alternative residential locations and a set of alternative employment opportunities. The individual examines the costs and benefits of any residential location or job offer. These costs and benefits are a function of many characteristics such as personal and household characteristics, current income and residential location characteristics. The individual maximises utility by moving through different residential location states and by changing labour market state, while taking into account once-only costs associated with changing residential location. However, we ignore search costs. We assume that an individual is continuously engaged in search for a better residential location and in search for a 
job. The rates at which a job or a residence is offered, the so-called job and housing offer arrival rates, are determined by macro factors like job availability and housing supply, but also by individual-specific characteristics. The job and housing offer arrival rates are assumed to be exogenous.

Our model distinguishes between local and national jobs. A local job is defined as a job which is within feasible commuting distance, whereas a national job is defined as a job situated outside the local labour market, i.e. outside feasible commuting distance. Hence, the individual will have to move in order to accept a national job offer. In order to avoid further specificational complexities, we assume that a job offer in the national labour market carries with it a residential offer, that is, it is a draw from a bivariate distribution of jobs and residential offers. As a result of the distinction between local and national job search, commuting distance is taken into account implicitly in our model rather than explicitly as in Van Ommeren et al. (1997, 2000). Hence, we are able to set up a relatively simple model without losing any important insights into optimal search behaviour of nonemployed individuals.

In the job search literature, jobs are characterised by wages and workers are assumed to prefer higher wages (see the overview paper by Devine and Kiefer 1993). In the residential mobility literature, individuals are assumed to prefer a higher place utility to a lower place utility, where place utility is defined as the utility experienced in a certain location net of housing costs, which depends on the specific benefits of the residential location (see Wolpert 1965, Yapa et al. 1971). In the theoretical model, we think of place utility as being equivalent to the concentration of ethnic compatriots in the area of residence. We extend these standard assumptions by letting jobs be characterised by wages as well as their geographical location relative to the current residential location: within commuting distance or not.

Some of the results derived from the basic model of Damm and Rosholm (2003) are similar to those derived by Van Ommeren et al. (1997, 2000). Most importantly, the optimal search strategies are reservation strategies so that job and residential mobility behaviour of jobless individuals are described by transition rates which are the product of offer arrival rates and offer acceptance probabilities, and all transition rates depend on labour market as well as housing market characteristics.

The most important implications of the model are the following. First, the reservation wage for jobs in the local labour market is lower than for a job with similar place utility in another labour market, because the latter 
involves costs of residential mobility. Second, the reservation wage for local jobs is lower, the higher the place utility. This implies that the transition rate into local jobs is an increasing function of place utility, ceteris paribus. This is not a network effect, but rather it stems from the fact that individuals must be compensated in order to induce them to live and work in a location offering low place utility, e.g. due to lack of immigrant networks. This potentially leads to a negative employment effect of dispersal policies, the aim of which is to disperse immigrants as to expose them to the natives. Third, the reservation wage for jobs outside the local labour market is increasing in the place utility, implying that individuals living in less immigrant-dense areas are more likely to accept jobs involving a residential move. The intuition is the same as that above. Fourth, the reservation place utility is obviously increasing in the current place utility, implying that imigrants placed in less immigrant-dense areas are more likely to move away to conduct job search in a more 'friendly' environment. In sum, dispersal policies have the likely consequence that individuals are less likely to accept jobs locally. Instead, they may postpone their job finding until they have located a residence and/or a job in a location which yields higher place utility. From the theoretical model and arguing that the local reservation wage effect dominates the national reservation wage effect, we would thus expect dispersal policies to delay refugees' job finding. Moreover, an implication of this would be that mover should observe higher job finding rates. Of course, in real life, place utility is likely to depend on many other factors than the density of fellow countrymen, and in the empirical models we try to capture this dependency by introducing a vector of residence-specific traits into the equations for residential mobility as well as job finding. The theoretical model thus gives rise to the following reduced-form specifications of the job finding rate, $h_{u}$, and the geographical mobility rate, $h_{r}$ :

$$
h_{u}=h_{u}\left(t_{u}, b, X\right)
$$

and

$$
h_{r}=h_{r}\left(t_{r}, c, X\right)
$$

where $t_{u}$ and $t_{r}$ denote the elapsed spell lenght of unemployment and current region of residence, $b$ denotes the social welfare benefits level, $c$ the once-only costs of moving region of residence and $X$ is a vector of variables including demographic and socio-economic characteristics of the individual, 
labour and housing market characteristics influencing the reservation values and offer arrival rates, and variables of location characteristics affecting the current place utility.

Moreover, due to the process according to which refugee immigrants acquire host-country-specific human captial (such as language and cultural understanding), we expect the job offer arrival rate, irrespective of regional characteristics, to be very low initially and then to increase gradually as refugee immigrants become more and more employable and acquire more knowledge about the local labour market. We therefore expect the job finding rate to increase over time. We believe host-country language proficiency to be an important prerequisite for employability at today's Scandinavian labour market, because as argued by Rosholm et al. (2000) the transition from an industrial society to the IT society has changed the traditional production methods and brought forward new economic activities which to a larger extent than before requires employees with host-country language proficiency.

Turning to labour market characteristics which may influence the job offer arrival rate in a given region, we expect the regional unemployment rate to be a key variable, influencing the regional job offer arrival rate negatively. Another factor which may influence the regional job offer arrival rate is the extent to which local councils co-operate with local firms with respect to qualifying refugees for the host-country labour market, for instance by use of private jobtraining programmes as part of Active Labour Market Programmes. The extent to which such co-operation takes place is unobserved to us, but we believe that it may be systematically related to the share of right-wing versus left-wing votes at the latest local election, and therefore we include the share of right-wing votes at the latest local election as a proxy in the empirical analysis.

A labour market characteristic of potential importance for the reservation wage is the share of the region's jobs located in the municipality in which a person lives. The idea is that individuals are likely to set a lower reservation wage when offered a job in close proximity to the place of residence than when offered an otherwise similar job further away, since the individual requires to be compensated for the higher commuting costs in the latter case. Living in a municipality with a high share of the jobs in the region may therefore influence the job finding rate positively.

Turning to housing market factors which may influence the hazard rate of relocation out of a given region, the residence offer arrival rate is likely to increase over time as immigrants acquire increased knowledge about the 
housing market and increased access to the different sectors of the housing market in the host country. ${ }^{7}$ An increasing residence offer arrival rate is likely to imply an increasing hazard rate of geographical mobility over time. In addition, learning about match quality takes time which may also contribute to an increasing hazard rate of geographical mobility within a given residential spell. On the other hand, an individual is likely to become increasingly attached to the area in which he lives over time spent in that location which may cause the hazard rate of geographical mobility to decrease over time spent residing in a given location.

Similarly, we expect the local residence offer arrival rate to be increasing in percentage of public housing in the total local housing stock, which all other things equal reduces the hazard rate of geographical mobility, since a residential move aiming at adjustment of housing consumption is likely to take place within the current local area.

We argue in the following that the current place utility is increasing with local concentration of fellow countrymen, local access to vocational educational institutions and local access to amenities offered by larger cities.

Recent immigrants may derive high place utility from living close to fellow countrymen for the following two reasons. Firstly, recent immigrants are likely to have limited information about the host country whereas ethnic enclaves constitute well-known cultural, social and economic environments which facilitate their adjustment to the new society (Piore 1979; Kobrin and Speare 1983). Specifically, residence in an ethnic enclave strengthens feelings of security, solidarity and identity within the group due to the common cultural background. Furthermore, the local ethnic network may establish social institutions that support the members, among others in relation to the rest of the society. In addition, local ethnic labour markets may develop further employment opportunities. Finally, the ethnic network may convey information about employment opportunities outside the residential area. Secondly, living near ethnic enclaves helps to reduce the costs of consumption of so-called ethnic goods defined as the consumption characteristics of an ethnic group not shared with the host population, broadly defined to include market and non-market goods and services, including social interactions for themselves

\footnotetext{
${ }^{7}$ In the Danish case, the housing market is characterised by a highly regulated rental housing sector and a relatively large owner housing sector. New immigrants in Denmark have easiest access to public housing, whereas contacts with native Danes are useful for entrance into the private rental housing market, and savings and five years of prior residence in Denmark are required in order to enter the owner housing market.
} 
and their children with people of the same origin (Chiswick and Miller 2001).

We believe the current place utility to be increasing in the size of the local population, because recent immigrants tend to settle in larger cities (Bartel 1989) which may be due to a preference for residing near airports which facilitate contact with old networks abroad, due to access to a large variety of goods and services in general and due to the local population being more accustomed to interactions with foreigners.

New refugee immigrants are likely to prefer living in a local area with many institutions for vocational and higher education for numerous reasons. Firstly, due to lack of vocational education from the source country, for instance because of leaving the source country at an early age or lack of financial means for obtaining an education or because of the education being interrupted by war. Secondly, due to lack of approval of foreign educations in the host country. Thirdly, due to a need for upgrading the skill level for employability in the host country labour market, for instance due to a high minimum wage and a mismatch between low-skilled job demand and job supply in the host country.

Finally, note that refugee immigrant groups which reside in areas with similar residence and labour market characteristics are likely to have different job finding and relocation hazard rates due to differences in demographic and socio-economic characteristics affecting the offer arrival rates and reservation values. We, therefore, control for demographic and socio-economic background in the empirical estimation of the importance of residence and labour market characteristics for the relocation and job hazard rates.

\section{Data}

The data used in the empirical analysis stem from three sources. First, our microdata come from longitudinal administrative registers of Statistics Denmark on the immigrant population in Denmark 1984-2000 from which we have extracted a panel covering the population of male immigrants aged 18-59 from refugee-sending countries who immigrated to Denmark during October 1985 to December 1997 and therefore subjected to the first Danish Dispersal Policy. Second, we use annual time-series data on municipality characteristics from Statistics Denmark's website 'Statistik Banken', annual data from 1986 to 1998.

The immigrant data set contains information on a large number of in- 
dividual characteristics such as demographic, labour market and residential characteristics of immigrants. The data allow us to construct event spells with a sequence of states and dates of transitions between states. In this study, the two main states of interest are time until first job and time-ofliving in a given municipality. Specifically, we have used the information on municipality of residence and date of residential mobility into a new municipality to construct residential spells for each individual. ${ }^{8}$ The residential spell durations are measured in months. Note that we ignore residential moves within a municipality when constructing residential spells, since such moves tend to be carried out for housing consumption reasons rather than employment related reasons. In addition, we have made use of the labour market spells of immigrants for the period 1984-1997 constructed by the Institute of Local Government Studies to construct the first non-employment spell (sum of time spent out of the labour force and time spent as unemployed prior to the first job) for male refugee immigrants, also measured in months. Employment covers labour market states such as employment, selfemployment and assistant spouse, but exludes participation in active labour market programmes and leave schemes.

Although the immigrant data set is a very rich data set, it has a few weaknesses for the present analysis. First, it does not contain information on the admission category of immigrants. Second, individuals are not observed from the first month after immigration, but instead from the year following the year of immigration. Third, the data set lacks information on the municipality of placement for refugee immigrants.

We have dealt with the first data problem by applying an algorithm based on country of origin and year of first immigration to Denmark of the individual to extract immigrants from countries which were refugee-sending countries (17 countries) in known periods during 1985-1996. The validity of the algorithm was investigated in a related paper by Damm (2003a) by comparison with official figures on permits of stay granted to asylum seekers by calendar year and country of origin; it was found to be valid.

We have taken account of the third data issue by applying a rather complicated algorithm to identify the municipality of placement from the potential municipality of temporary housing. Use of the algorithm requires an individ-

\footnotetext{
${ }^{8}$ The data set is informative about the individual's county and municipality of residence (at the end of the year in case the person have moved during the year) and the date of the last residential move (by the end of the year).
} 
ual to be observed the first two years following the year of immigration. For further details see Damm (2003a). In case an individual is found to live in temporary housing when first observed in our register data, time until relocation away from the municipality of placement and time until the first job start at the time of relocation to the municipality of placement. Also note that our data do not allow us to distinguish the around $10 \%$ of new refugee immigrants who found the initial place of residence in Denmark on their own from the around $90 \%$ of new refugee immigrants who were initially placed in a certain location by DRC.

The second data problem gives rise to between 1 and 12 months of left censoring of the first non-employment spell, henceforth used to denote 'time since immigration until exit from non- or unemployment to the first job', and the spell of residence in the municipality of placement for the $89 \%$ of individuals who were found to live in the municipality of placement when first observed in the data. We have not taken account of left censoring in the econometric model. This implies that all non-employment and residential spells are treated as fresh spells, which leads to biased parameter estimates, if the processes are not exponentially distributed. However, given the data limitations, this is a shortcoming we have to accept. The complications introduced by proper treatment of left-censored spells would leave us unable to deal with the endogeneity-of-geographical-mobility issue which is the focus of the present paper.

The flow sample of male refugees aged 18-59 who immigrated during October 1985 to December 1997, who were observed for at least two consecutive years following the year of immigration and for whom labour market spells were constructed consists of 21,015 individuals. For each of these individuals, we have kept one non-employment spell, namely the first non-employment spell of that person and all of his residential spells prior to the first job. The observation period for an individual spans from the first year following immigration, at the earliest January 1986, until occurrence of the first transition from non-employment to employment or if no such transition occurs before the last observation for that individual, generally in 1997, the spell is treated as right-censored. The flow sample is merged with time-series data on the current municipality of residence. The time series data include local and regional labour market characteristics, the local population composition and local housing market characteristics.

Descriptive statistics on first non-employment spells are given in Table 4.1. It is seen that of the 21,015 individuals slightly more than half of the in- 
dividuals do, within the observation period, experience employment at some time, on the average after 35 months. Slightly less than half of the individuals thus do not experience employment within the observation period. Because these latte spells are right-censored, the overall mean duration of first non-employment spell of 43 months is downward biased.

Table 4.1 Descriptive statistics on non-employment spells

\begin{tabular}{lllll}
\hline \hline & Frequency & Distr. (\%) & Mean duration & Std. dev. \\
\hline Completed & 10,940 & 52.1 & 35.3 & 28.3 \\
Right-censored & 10,075 & 47.9 & 51.8 & 36.8 \\
\hline All & 21,015 & 100 & 43.2 & 33.7 \\
\hline \hline
\end{tabular}

Table 4.2 shows that the subsequent employment spell for refugees who exit to employment during the observation period on average lasts around a year. $29 \%$ of the spells last less than four months.

Table 4.2 Descriptive statistics on the subsequent employment spells

\begin{tabular}{lll}
\hline \hline Duration (months) & Distr. (\%) & Mean duration (Std. dev.) \\
\hline $1-3$ & 29.48 & \\
$4-6$ & 20.15 & \\
$7-12$ & 24.16 & \\
$13-24$ & 16.51 & \\
$25-36$ & 4.31 & $11.45(16.10)$ \\
$37-136$ & 5.39 & \\
\hline All & 100.00 & \\
\hline \hline
\end{tabular}

Descriptive statistics on residential spells are given in Tables 4.3 and 4.4. In Table 4.3, it is seen that the analysis is based on a total of 30,509 residential spells, of which around $32 \%$ were completed at the time of the first transition into job. The observed mean duration of residential spell is 30 months, which again is downward biased due to the high fraction of residential spells which were uncompleted at the end of the observation period.

Table 4.3 Descriptive statistics on residential spells

\begin{tabular}{lllll}
\hline \hline & Frequency & Distr. (\%) & Mean duration & Std. dev. \\
\hline Completed & 9,706 & 31.8 & 19.5 & 18.4 \\
Right-censored & 20,803 & 68.2 & 34.5 & 28.6 \\
\hline All & 30,509 & 100 & 29.7 & 26.7 \\
\hline \hline
\end{tabular}


Table 4.4 shows the distribution of the residential spell count variable $m$, i.e. the probability that a residential spell in the sample is the first, second, up to the sixth (or more) residential spell of an individual. It is seen that of the 21,015 individuals sampled, 6,978 have completed at least one residential spell, i.e. one third of the sampled individuals have made at least one relocation to another municipality - before finding their first job during the observation period. Finally, around $9 \%$ of the sampled individuals $(1,849)$ have completed at least two residential spells, i.e. they have moved at least twice across municipality borders.

Table 4.4 Distribution of residential spell count variable $m$ and mean duration of residential spells.

\begin{tabular}{lllll}
\hline \hline Spell no. & Frequency & Distr. (\%) & Mean duration & St.dev. \\
\hline 1 & 21,015 & 68.9 & 28.7 & 26.5 \\
2 & 6,978 & 22.9 & 32.3 & 27.6 \\
3 & 1,849 & 6.1 & 32.0 & 26.1 \\
4 & 502 & 1.7 & 29.7 & 24.7 \\
5 & 133 & 0.4 & 25.9 & 21.0 \\
6 or more & 32 & 0.1 & 18.3 & 16.7 \\
\hline All & 30,509 & 100.0 & 29.7 & 26.7 \\
\hline \hline
\end{tabular}

When estimating the effect of relocation on the employment prospects, we will allow the effect of first relocation to be different from the effect of further relocations. The reason is that because employability is likely to increase over time spent in the host country, we believe that later relocations are more likely to have been carried out for employment reasons than the first relocation. We therefore divide the sample into three subgroups: stayers (in the municipality of assignment), movers once, movers more than once. When comparing the mean duration of first non-employment spell between these subgroups, as is done in Table 4.5, it is seen that the mean duration of completed non-employment spell is positively correlated with the number relocations made. This is probably just a spurious finding; the longer the non-employment spell, the more likely is it that an individual has had several residential spells. Still, it shows the pattern in the raw data, and it illustrates the importance of using the right econometric tools for such an analysis, since our estimation results show the opposite causal relation between mobility and non-employment duration; see the next section. 
Table 4.5 Descriptive statistics on non-employment spells for different supgroups.

\begin{tabular}{lllll}
\hline \hline Spell type by subgroup & Frequency & Distr. (\%) & Mean duration & Std. dev. \\
\hline Stayers: & & & & \\
Completed & 7,717 & 55.0 & 28.4 & 24.2 \\
Right-censored & 6,320 & 45.0 & 41.3 & 31.3 \\
\hline Movers once: & & & & \\
Completed & 2,444 & 47.7 & 46.2 & 28.9 \\
Right-censored & 2,685 & 52.3 & 60.5 & 36.5 \\
\hline Movers more than once: & & & & \\
Completed & 779 & 42.1 & 69.5 & 28.4 \\
Right-censored & 1,070 & 57.9 & 92.0 & 33.8 \\
\hline \hline
\end{tabular}

Table 4.6 Initial geographical distribution of refugees. Subgroups: Movers vs. stayers.

\begin{tabular}{l|lll}
\hline \hline Size of municipality of placement & Small & Medium & Large \\
\hline Subgroup: & & Distr. (\%) & \\
Stayers & 9.6 & 57.5 & 32.9 \\
Movers once & 19.8 & 62.3 & 17.9 \\
Mover more than once & 16.7 & 61.0 & 22.3 \\
\hline All & 12.7 & 59.0 & 28.3 \\
\hline \hline
\end{tabular}

We now turn to the geographical settlement and relocation pattern of the refugees. Denmark is administered at three levels: the state, the county and the municipal level. Denmark has 14 counties, two county municipalities and 275 municipalities. The geographical distribution of the refugees across counties is shown in the Appendix, Table A.2. The refugees appear to have been equally distributed across counties (relative to the county population) with one exception, the already immigrant-dense Copenhagen county which relatively received fewer placed refugees. The geographical distribution of refugees across municipalities in presented in Table 4.6, where small municipalities are defined as having less than 10,000 inhabitants, medium-sized municipalities as having 10-100,000 inhabitants and large municipalities as having more than 100,000 inhabitants. The category 'large municipalities' at least in part includes the four larger cities in Denmark, Copenhagen, Århus, Odense and Ålborg which are situated in Copenhagen and Frederiksberg county municipalities, Århus county, Funen county and North Jutland county, respectively. In 1993, 132 municipalities belonged to the category 
'medium-sized' and 139 municipalities to the category 'small'. The categories large and medium-sized municipalities mainly cover urban areas, while the category 'small' covers both smaller urban areas and rural districts. Table 4.6 shows that more than $13 \%$ of refugees were placed in small municipalities, $59 \%$ in medium-sized and the remaining $28 \%$ in large municipaties. The geographical distribution of the population as such was the following in the 1990s: $18 \%$ lived in small municipalities, $61 \%$ in medium-sized municipalities and $21 \%$ in large municipalities. In consequence, the refugees in our sample were overrepresented in the larger municipalities and underrepresented in the smaller municipalities. However, refugees who subsequently moved away from the municipality of placement, henceforth termed 'movers', actually had an initial distribution across municipalities which almost corresponded to the overall distribution of the population. So compared to stayers among placed refugees, movers were substantially overrepresented in the smaller and medium-sized municipalities and considerably underrepresented in the larger municipalities.

Table 4.7 investigates the relocation pattern of non-employed refugee immigrants who leave their municipality of residence. We see that although $50 \%$ of non-employed individuals in the small municipalities leave the municipality of placement, their relocations constitute only $19 \%$ of the overall relocations out of the municipality of assignment by non-employed individuals. I.e. relocations out of medium and large municipalities constitute the remaining $81 \%$ of the relocations out of the municipality of assignment. Where did the non-employed refugee movers relocate to? From Table 4.7. we see that $94 \%$ of the first-time relocations were relocations to medium or large municipalities. The net result of these relocation patterns is an increased concentration of non-employed refugee immigrants in the larger municipalities. The larger municipalities are seen to have a net in-migration rate (relative to the total number of movers among placed, non-employed refugees) of 20\% (from 19 to $39 \%)$. 
Table 4.7 Relocation pattern of first-time movers.

\begin{tabular}{l|lll|l}
\hline \hline $\begin{array}{l}\text { Size of municipality } \\
\text { of placement: }\end{array}$ & $\begin{array}{l}\text { Size of } \\
\text { Small }\end{array}$ & $\begin{array}{l}\text { municipality } \\
\text { Medium } \\
\text { Distr. (\%) }\end{array}$ & $\begin{array}{l}\text { of destination: } \\
\text { Large }\end{array}$ & All movers \\
\hline Small & 1.7 & 12.0 & 5.3 & 19.0 \\
Medium & 3.3 & 30.2 & 28.5 & 62.0 \\
Large & 0.9 & 12.5 & 5.7 & 19.1 \\
\hline All movers & 5.9 & 54.7 & 39.4 & 100 \\
\hline \hline
\end{tabular}

In Table 4.8 we investigate whether there are differences in the relocation pattern out of the municipality of assignment for non-employed refugee immigrants between subgroups of movers, i.e. one-time movers and movers with additional relocations. We do find some evidence of differences in the relocation pattern, namely that one-time movers are more likely to make a relocation to a large municipality and less likely to make a relocation to a small or medium-sized municipality than movers who make at least one additional relocation.

Table 4.8 Relocation pattern of first-time movers. Subgroups.

\begin{tabular}{l|lll|l}
\hline \hline Subgroup of movers: & $\begin{array}{l}\text { Size of } \\
\text { Small }\end{array}$ & $\begin{array}{l}\text { municipality } \\
\text { Medium }\end{array}$ & $\begin{array}{l}\text { of destination: } \\
\text { Large }\end{array}$ & \\
\hline One-time movers: & \multicolumn{3}{|c}{ Distr. (\%) } & All \\
\hline $\begin{array}{l}\text { Size of municipality } \\
\text { of placement: }\end{array}$ & & & & \\
$\begin{array}{l}\text { Small } \\
\text { Medium }\end{array}$ & 1.4 & 12.6 & 5.8 & 19.8 \\
Large & 2.7 & 27.7 & 31.9 & 62.3 \\
\hline All & 0.7 & 10.9 & 6.3 & 17.9 \\
\hline Movers more & 4.8 & 51.2 & 44.0 & 100 \\
than once: & & Distr. (\%) & All \\
\hline Size of municipality & & & & \\
of placement: & & & & 16.7 \\
Small & 2.3 & 10.4 & 3.9 & 61.0 \\
Medium & 5.0 & 37.1 & 18.9 & 22.3 \\
Large & 1.5 & 17.0 & 3.9 & 100 \\
\hline All & 8.8 & 64.5 & 26.7 & \\
\hline \hline
\end{tabular}


Table 4.9 Relocation pattern of second-time movers.

\begin{tabular}{l|lll|l}
\hline \hline $\begin{array}{l}\text { Size of first destination } \\
\text { municipality: }\end{array}$ & $\begin{array}{l}\text { Second } \\
\text { Small }\end{array}$ & $\begin{array}{l}\text { destination } \\
\text { Medium }\end{array}$ & $\begin{array}{l}\text { municipality: } \\
\text { Large }\end{array}$ & All movers \\
\hline & & Distr. (\%) & & \\
Small & 1.1 & 5.1 & 2.5 & 8.8 \\
Medium & 3.0 & 28.7 & 32.8 & 64.5 \\
Large & 0.8 & 18.5 & 7.4 & 26.7 \\
\hline All movers & 5.0 & 52.3 & 42.7 & 100 \\
\hline \hline
\end{tabular}

Table 4.9 shows the relocation pattern of second-time movers. As for first-time relocations, we see that relocations out of medium-sized municipalities constitute the main part of the second-time relocations. Comparison of Tables 4.9 and 4.7 shows a difference between first-time and second-time relocation patterns, namely that relocations out of small municipalities are seen to constitute a lower fraction of second-time relocations than first-time relocations, or in other words that relocations out of large municipalities constitute a higher fraction of second-time relocations than first-time relocations. The pattern of choice of municipality of destination for second-time movers corresponds to the pattern found for one-time movers. $95 \%$ of the second-time relocations were relocations to medium or large municipalities. The net result of the relocation pattern for second-time jobless movers is, as it was for the first relocation, an increased concentration of jobless refugee immigrants in the larger municipalities which experience a net in-migration rate of $16 \%$. 
Table 4.10 Initial and 'final' geographical distribution of refugees. Per cent. Subgroups: Completed vs. right-censored non-employment spells.

\begin{tabular}{l|lll|l}
\hline \hline $\begin{array}{l}\text { Size of municipality of residence: } \\
\text { Subgroups: Non-employment spell }\end{array}$ & Small & Medium & Large & All \\
\hline & \multicolumn{4}{|c|}{ Initial distr. } \\
Completed & 13.2 & 62.3 & 24.5 & 100.00 \\
Right-censored & 12.1 & 55.4 & 32.5 & 100.00 \\
\hline All & 12.7 & 59.0 & 28.3 & 100.00 \\
\hline & \multicolumn{4}{|c}{ 'Final' distr. } \\
Completed & 9.5 & 60.7 & 29.9 & 100.00 \\
Right-censored & 5.9 & 49.3 & 44.8 & 100.00 \\
\hline All & 7.7 & 55.2 & 37.0 & 100.00 \\
\hline \hline
\end{tabular}

Note: 'Final' geographical distribution refers to the geographical distribution at the end of the individuals' first non-employment spell (completed or rightcensored).

Table 4.10 presents descriptive evidence that initial conditions in terms of the municipality of placement have influenced the labour market integration process of refugees. Refugees who found employment during the observation period were initially overrepresented in the small and medium-sized municipalities. The table also shows the geographical distribution of individuals at the end of the individuals' first non-employment spell. Refugees who found employment during the observation period were overrepresented in the small and medium-sized municipalities and underrepresented in the large municipalities compared to refugees who did not succeed in finding employment during the period of observation. Table A.3 in the Appendix repeats this exercise at the county level. Refugees who found employment were initially overrepresented in the counties of Ringkø bing, Ribe and Vejle and considerably underrepresented in Copenhagen and Frederiksberg County Municipality and Funen County. At the end of the individuals' first non-employment spell, refugees who found a job were overrepresented in all other counties than those in the Greater Copenhagen area, Funen and Storstrøm, but especially in the same three counties as initially. In the present analysis the Greater Copenhagen area is defined as Copenhagen and Frederiksberg County Municipality and Copenhagen County.

Table A.1 in the Appendix shows the initial sample characteristics for the three subsamples. The second column shows the initial characteristics for persons with no relocation out of the municipality of placement, the third 
column shows those for persons with one relocation (out of the municipality of placement), the fourth column those for persons with more than one relocation while the last column gives the average initial values for the entire sample. On average, stayers and movers differ both with respect to demographic characteristics and the characteristics of their municipality of placement. Compared to stayers, movers tend to be slightly younger, have less children and be unmarried. In addition, refugees from Africa and the Middle East tend to be movers rather than stayers. The characteristics of the municipality of placement also seem to matter for whether an individual moves or stays. Compared to stayers, movers were initially overrepresented in small and medium-sized municipalities (this is also seen from Table 4.6), but also in the Greater Copenhagen area. In addition, movers were overrepresented in municipalities with relatively low percentages of immigrants and low concentrations of fellow countrymen, municipalities with a low share of the county jobs, few institutions for vocational and higher education and less public housing in percentage of the local housing stock. In contrast, the regional unemployment rate of the municipality of placement is almost the same for movers and stayers. Movers who make more than one relocation and movers who make exactly one relocation seem to differ mainly with respect to their demographic characteristics. On average, the former group consists of individuals who are younger, have less children and are single to a higher extent than individuals in the latter group. Unfortunately, we do not have information on host-country language skills, highest completed level of education or work experience obtained prior to immigration.

For information about how the various variables used in the empirical analysis were constructed, readers are referred to the Appendix.

\section{Model specification}

Let us first define the state space. Our key variable of interest is time until first transition from non-employment to employment. Time until the first transition into employment is the sum of time spent outside the labour force and time spent as unemployed prior to first employment spell.

The process we consider can thus be described as follows: Let there be two labour market states, non-employment and employment. The first year after being granted asylum, the first non-employment spell begins, and parallel to the first non-employment spell another process begins, measuring time until 
relocation to another municipality. This parallel process is sequential in the sense that consecutive residential spells are measured separately. If a person finds a job before making a (further) relocation, the time until relocation is treated as right-censored. In this way, the selection process into relocation is explicitly modelled. Models similar to ours have been used to study the effect of punitive sanctions and training on the exit rate out of unemployment (Card and Sullivan 1988; Gritz 1993; Bonnal et al. 1997; Abbring et al. 1997; Bolvig et al. 2003; Van den Berg et al. 2004, to name just a few) and to study the effect of having children on marriage duration (Lillard 1993) as well as the effect of marriage dissolution on the death rate (Lillard and Panis 1996).

\subsection{Econometric specification}

Let the random variable $T_{u}$ denote the duration of first non-employment spell, and $T_{r}$ the duration of residential stay in a municipality. In addition, let $\mathrm{m}$ be a scalar denoting whether a residential spell is the first, second, third up to the $M$ th residential spell for that person. Finally, let $\mathrm{x}_{u}$ and $\mathrm{x}_{r}$ be time-varying vectors of observed covariates and $\mathrm{v}_{u}$ and $\mathrm{v}_{r}$ be unobserved covariates.

The key concept in duration models is the hazard rate. The continuous time hazard rate is the transition rate out of the state at time $t$, conditional on being in the state at least until $t$, i.e.

$$
h(t)=\lim _{\Delta \rightarrow 0} \frac{\operatorname{Pr}(t<T \leq t+\Delta \mid T>t)}{\Delta}
$$

The overall model is a bivariate mixed proportional hazard (MPH) model. Hence, the hazard functions for residential spells and non-employment spells are assumed to be MPH functions,

$$
\begin{gathered}
h_{r}\left(t_{r m} \mid x_{r}\left(t_{r m}\right), v_{r}\right)=\lambda_{r}\left(t_{r m}\right) \cdot \varphi_{r}\left(x_{r}\left(t_{r m}\right)\right) \cdot \exp \left(v_{r}\right), m=1, \ldots, M \\
h_{u}\left(t_{u} \mid t_{r m}, x_{u}\left(t_{u}\right), v_{u}\right)=\lambda_{u}\left(t_{u}\right) \cdot \varphi_{u}\left(x_{u}\left(t_{u}\right)\right) \cdot \exp \left(\delta_{1} I\left(t_{r 1} \leq t_{u} \mid t_{u}<t_{r 1}+t_{r 2}\right)\right) \\
\cdot \exp \left(\delta_{2} I\left(t_{r 1}+t_{r 2} \leq t_{u} \mid t_{u}<t_{r 1}+t_{r 2}+t_{r 3}\right)\right) \cdot \ldots \cdot \exp \left(\delta_{M} I\left(\sum_{m=1}^{M} t_{r m} \leq t_{u}\right)\right) \cdot \exp \left(v_{u}\right)
\end{gathered}
$$


where $x_{r}(\cdot)$ includes a set of indicators for whether it is the first, second, $\ldots, m$ th residential spell of the individual. $\mathrm{I}($.$) is an indicator function, which$ is 1 if its argument is true and 0 otherwise. The hazard into employment is consequently allowed to move to another level at the moment at which the duration of a residential spell is completed. $\delta_{m}, m=1, \ldots, M$, are the main parameters of interest since the estimate of $\delta_{m}$ is the causal effect of $t_{r m}$ on $t_{u}$ and can be interpreted as a treatment of the treated effect. However, in the empirical analysis we restrict the causal effect of relocations subsequent to the first relocation to be the same, i.e. $\delta_{2}=\delta_{3}=\ldots=$ $\delta_{M}$. Note that a significantly positive (negative) estimate of $\delta_{m}$ means that the level of the individual job finding rate increases (falls) by a fixed factor at the time of residential mobility. This stochastically reduces (increases) the remaining duration of non-employment in comparison to the case where residential mobility occurs at a later point in time or not at all.

The likelihood contribution of a residential spell and non-employment spell is

$$
\begin{aligned}
& L_{r m}=h_{r}\left(t_{r m} \mid x_{r}\left(t_{r m}\right), v_{r}\right)^{d_{r}} \cdot \exp \left[-\int_{0}^{t_{r m}} h_{r}\left(s \mid x_{r}(s), v_{r}\right) d s\right] \\
& L_{u}=h_{u}\left(t_{u} \mid t_{r m}, x_{u}\left(t_{u}\right), v_{u}\right)^{d_{u}} \cdot \exp \left[-\int_{0}^{t_{u}} h_{u}\left(s \mid x_{u}(s), v_{u}\right) d s\right]
\end{aligned}
$$

respectively, where $d_{r}$ and $d_{u}$ are non-censoring indicators (taking the value 1 if an observation is not censored, and 0 otherwise).

We choose a flexible model for the unobserved covariates. We allow for a separate unobserved covariate in each of the hazard rates denoted $\mathrm{v}_{u}$ and $\mathrm{v}_{r}$ and allow for arbitrary correlation between them in order to avoid bias in the estimate of the effect of residential mobility.

The total contribution to the likelihood function for a single individual is then

$$
L=\int_{V_{u}} \int_{V_{r}} L_{u}\left(t_{u} \mid t_{r}, X_{u}(t), V_{u}\right) \cdot \prod_{m=1}^{M} L_{r m}\left(t_{r m} \mid X_{r}\left(t_{r m}\right), V_{r}\right) d G\left(V_{u}, V_{r}\right)
$$

where $\mathrm{G}(\cdot)$ is the joint cumulative distribution function for $V_{u}$ and $V_{r}$, and $M$ is the number of residential spells an individual experiences before finding the first job. 
We assume the marginal distributions of the unobserved terms, $\mathrm{F}\left(\mathrm{V}_{u}\right)$ and $\mathrm{F}\left(\mathrm{V}_{r}\right)$, to be discrete distributions with two unrestricted mass-point locations. Let $\mathrm{v}_{u}^{1}, \mathrm{v}_{u}^{2}, \mathrm{v}_{r}^{1}$, and $\mathrm{v}_{r}^{2}$ denote the four mass-points of $\mathrm{V}_{u}$ and $\mathrm{V}_{r}$, respectively. The associated probabilities are then as follows:

$$
\begin{array}{ll}
\operatorname{Pr}\left(V_{u}=v_{u}^{1}, V_{r}=v_{r}^{1}\right)=p_{1} & \operatorname{Pr}\left(V_{u}=v_{u}^{1}, V_{r}=v_{r}^{2}\right)=p_{2} \\
\operatorname{Pr}\left(V_{u}=v_{u}^{2}, V_{r}=v_{r}^{1}\right)=p_{3} & \operatorname{Pr}\left(V_{u}=v_{u}^{2}, V_{r}=v_{r}^{2}\right)=p_{4}
\end{array}
$$

with $0 \leq p_{i} \leq 1$ for $\mathrm{i}=1, \ldots, 4$, and $\sum_{i=1}^{4} p_{i}=1$. We normalise the distribution of the unobservables by letting $\exp \left(\mathrm{v}_{j}^{1}\right)=1$ for $j=u, r$.

The observed part of the individual-specific hazard is specified as: $\varphi_{j}\left(X_{j}(t)\right)$ $=\exp \left(X_{j}^{\prime} \beta_{j}\right), j=u, r$, where $X_{u}(t)=x_{u}(t)$ and $X_{r}(t)=x_{r}(t)$. The baseline hazard rates are assumed to be piecewise constant, i.e. $\lambda_{j}(t)=\exp \left(\alpha_{j k}\right), k=$ $1, \ldots, K_{j,} j=u, r$, where $K_{j}$ is the number of intervals for the baseline hazard of spell type $\mathrm{j}$. The length of the baseline intervals is chosen on the basis of the Kaplan Meier Hazard functions for exit to first job and exit from municipality of residence, see Figures 5.1 and 5.2. 
Figure 5.1

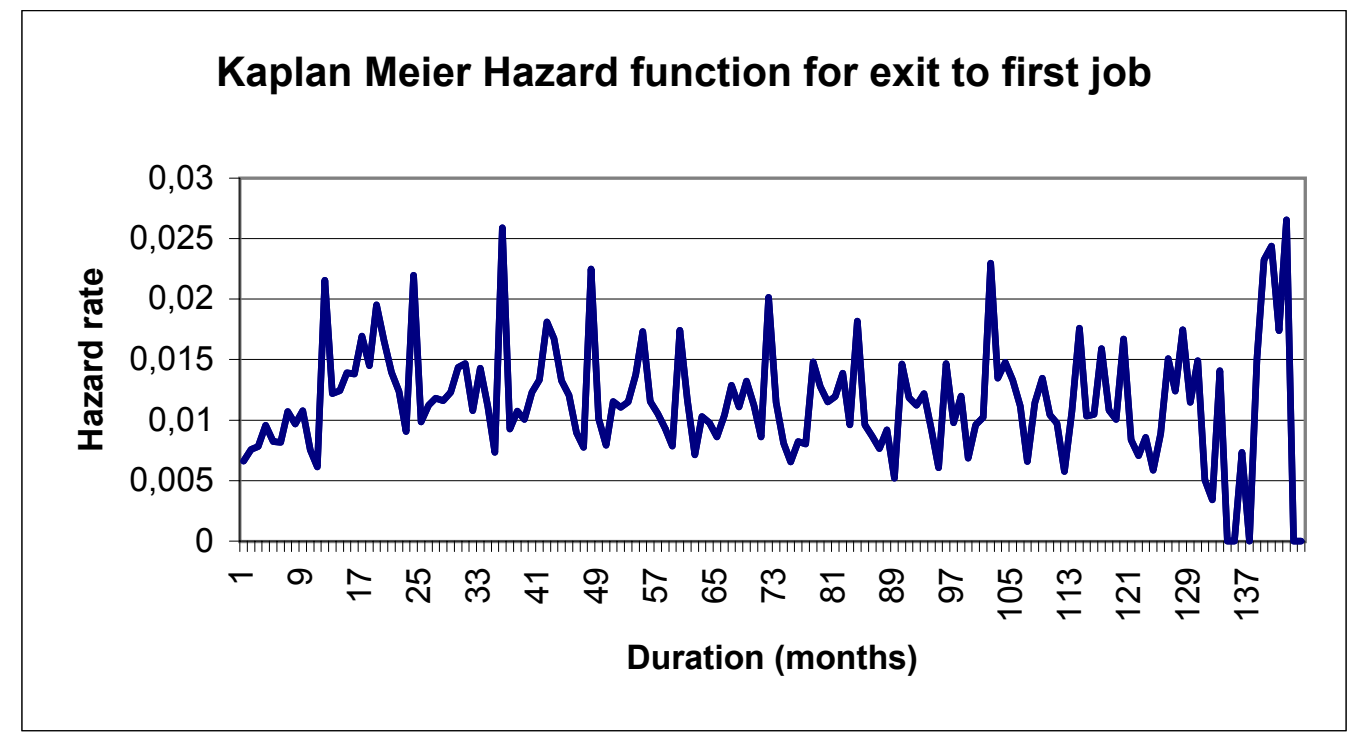

Figure 5.2

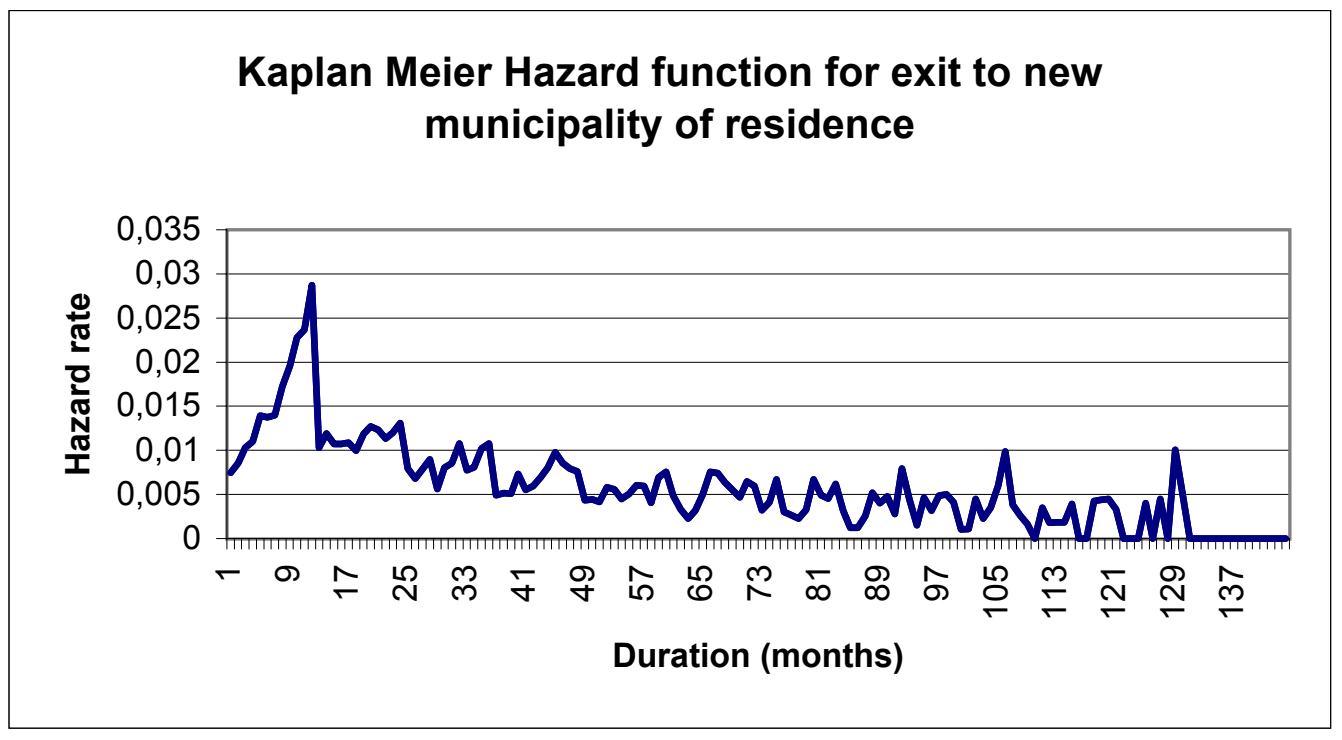


A recent working paper, Abbring and Van den Berg (2003), provides identification results for this model, the main identification issue being disentanglement of the treatment effect from the selection effect. If individuals with a treatment at time $t_{r}$ have relatively short (long) durations, $t_{u}$, it can be for two reasons: Either the individual treatment effect is positive (negative) or treated individuals have relatively high (low) values of $\mathrm{v}_{u}$ and would have left the state of interest relatively fast (slowly) anyway. Abbring and Van den Berg (2003) show that given an assumption of no anticipation of the realisation of the treatment the two effects can be disentangled without resorting to exclusion restrictions. ${ }^{9}$ However, individuals are allowed to know the (determinants of the) probability distribution of time until treatment. In particular, the timing of events conveys useful information on the treatment effect enabling identification of the treatment effect whereas the competing risks model embedded in the model enables identification of the selection effect. In addition to no anticipation, identification requirements are independence of $x_{r}$ and $x_{u}$ from $v_{i}, i=u, r$, and an assumption of existence of the first moment of $\mathrm{v}_{i}$ unless multiple observations are available for each $\mathrm{v}_{i}$ pair which they are not in the present context. If these identification requirements are met, the effect of residential mobility is identified. The identification argument is based on exogenous variation in the timing of events; if there is exogenous variation in the timing of mobility, it can be identified separately from the selection effect. The latter is based on unobserved individual heterogeneity, which is constant over the non-employment spell. The effect of mobility, however, does not appear in the non-employment hazard before mobility has occurred. This also illustrates why the assumption of 'no anticipation' is important. If the effect of mobility is present throughout the non-employment spell, we can not be sure to disentagle it from a selection effect.

It might be worthwhile to consider the extent to which the 'no anticipation' assumption is satisfied in the present context. Refugee immigrants (in fact, foreigners in general) with less than five years of residence in Denmark are not allowed to buy real estate (Law of Acquisition of Real Estate). Moreover, refugee immigrants have little access to the private rental housing market, for a number of reasons. First, due to extensive rent control which results in queues for private rental housing of mainly young persons

\footnotetext{
${ }^{9}$ I.e. the data is not required to contain a variable that affects the treatment assignment but does not affect the outcome of interest other than by way of treatment.
} 
and other persons excluded from the real estate housing market due to lack of savings or lack of right to buy real estate. Second, due to lack a Danish network that facilitate access to private rental housing by conveying informal information about housing vacancies in the private rental housing market. Third, due to potential discrimination of refugee immigrants by private landlords. Hence, the main option open to refugee immigrants is to apply for housing in the 'public housing' sector to which new refugee immigrants have relatively easy access, because socially and economically disadvantaged individuals with housing problems have priority to $25 \%$ of vacant housing units in the sector. In 1991, $52 \%$ of refugee immigrants aged 15 to 66 years were living in public housing, while only $15 \%$ of the Danish population aged 15 to 66 years lived in public housing. Moreover, the share of refugee immigrants who lived in public housing was even larger for recent refugee immigrants (Hummelgaard et al. 1995).

Renters in the public housing sector have 3 months' notice. Therefore, an apartment vacancy is often announced only 2-2.5 months prior to the apartment vacancy. An individual who has applied for a vacant apartment is likely to receive that information about two months before the actual apartment vacancy. Remember that individuals are allowed to know the distribution of residential spell durations, just not the actual date of mobility too long in advance. It seems to us that in the present context with fairly long residential spells that 2-3 months' anticipation is not a large problem.

\section{Empirical results}

The results of the bivariate mixed proportional hazard model with unobserved heterogeneity are presented in Table 6.1. The estimates of the parameters in the residential mobility equation are reported in column 2 while column 4 reports the parameter estimates of the non-employment duration equation. Standard errors of the selection equation parameter estimates are reported in column 3 while standard errors of the non-employment equation parameter estimates are reported in the last column. 
Table 6.1 Estimates from a bivariate MPH model. Part A.

\begin{tabular}{|l|ll|ll|}
\hline \hline & Relocation & & Employment & \\
\cline { 2 - 5 } Variables & Estimates & Std. err. & Estimates & Std. err. \\
\hline Age/100 & 1.454 & 1.137 & $2.988^{* * *}$ & 0.968 \\
Age/100 squared & $-3.799^{* *}$ & 1.615 & $-9.350^{* * *}$ & 1.368 \\
Married & $-0.056^{*}$ & 0.032 & -0.006 & 0.027 \\
Marital status change & $0.234^{* * *}$ & 0.046 & -0.072 & 0.049 \\
\# children 0-2 years/10 & $-1.297^{* * *}$ & 0.275 & $-2.734^{* * *}$ & 0.223 \\
\# children 3-17 years/10 & $-0.959^{* * *}$ & 0.127 & $-0.624^{* * *}$ & 0.107 \\
Poland & -0.021 & 0.110 & $0.769^{* * *}$ & 0.077 \\
Iraq & $0.137^{* *}$ & 0.067 & $0.368^{* * *}$ & 0.059 \\
Vietnam & $-0.621^{* * *}$ & 0.083 & $0.470^{* * *}$ & 0.059 \\
Sri Lanka & $-0.612^{* * *}$ & 0.064 & $1.121^{* * *}$ & 0.049 \\
No citizenship & 0.048 & 0.041 & $0.073^{*}$ & 0.040 \\
Ethiopia & 0.043 & 0.145 & $0.438^{* * *}$ & 0.127 \\
Afghanistan & 0.190 & 0.131 & $0.622^{* * *}$ & 0.122 \\
Somalia & $0.275^{* * *}$ & 0.079 & $0.445^{* * *}$ & 0.070 \\
Rumania & $-0.471^{* * *}$ & 0.169 & $1.561^{* * *}$ & 0.110 \\
Chile & -0.402 & 0.615 & $1.355^{* * *}$ & 0.229 \\
Bosnia-Herzegovina & -0.070 & 0.097 & $0.979^{* * *}$ & 0.079 \\
Ex-Yugoslavia (not BH) & -0.187 & 0.360 & $2.132^{* * *}$ & 0.175 \\
Former Yugoslavia & -0.041 & 0.195 & $0.899^{* * *}$ & 0.106 \\
Ethnic stock/10 & $-0.151^{*}$ & 0.078 & $0.407^{* * *}$ & 0.075 \\
Years of educ. lagged/10 & $0.799^{* * *}$ & 0.294 & 0.191 & 0.206 \\
log(income) lagged/10 & -0.053 & 0.035 & $0.266^{* * *}$ & 0.028 \\
Immigrat. year: 1985 & -0.019 & 0.072 & $0.301^{* * *}$ & 0.067 \\
Immigrat. year: 1986 & -0.015 & 0.056 & $0.255^{* * *}$ & 0.052 \\
Immigrat. year: 1987 & -0.065 & 0.060 & $0.188^{* * *}$ & 0.055 \\
Immigrat. year: 1988 & -0.009 & 0.058 & 0.079 & 0.056 \\
Immigrat. year: 1989 & 0.000 & 0.066 & 0.039 & 0.062 \\
Immigrat. year: 1991 & 0.070 & 0.060 & $0.107^{*}$ & 0.061 \\
\hline
\end{tabular}


Table 6.1 Estimates from a bivariate MPH model. Part B.

\begin{tabular}{|c|c|c|c|c|}
\hline & \multicolumn{2}{|l|}{ "Relocation } & \multicolumn{2}{|c|}{ Employment } \\
\hline Variables & Estimates & Std. err. & Estimates & Std. err. \\
\hline Immigrat. year: 1992 & 0.044 & 0.064 & $0.191^{* * *}$ & 0.061 \\
\hline Immigrat. year: 1993 & $0.130^{*}$ & 0.067 & -0.017 & 0.068 \\
\hline Immigrat. year: 1994 & 0.031 & 0.080 & -0.016 & 0.077 \\
\hline Immigrat. year: 1995 & $0.571^{* * *}$ & 0.094 & $-0.158^{*}$ & 0.087 \\
\hline Greater Copenhagen & $0.644^{* * *}$ & 0.046 & -0.020 & 0.042 \\
\hline Medium municipality & $0.182^{* *}$ & 0.080 & $0.607^{* * *}$ & 0.059 \\
\hline Small municipality & $0.584^{* * *}$ & 0.097 & $0.881^{* * *}$ & 0.077 \\
\hline$\%$ immigrants $/ 100$ & $-3.689 * * *$ & 0.759 & $-5.038 * * *$ & 0.602 \\
\hline Ethnic concentration/10 & $-0.290 * * *$ & 0.034 & $0.117^{* * *}$ & 0.027 \\
\hline Reg. unemp. rate/100 & $-3.368^{* * *}$ & 0.656 & $-2.626^{* * *}$ & 0.555 \\
\hline$\%$ of county jobs $/ 100$ & 0.349 & 0.244 & 0.024 & 0.191 \\
\hline \# educ. institutions/100 & $-2.052^{* * *}$ & 0.755 & $1.735^{* * *}$ & 0.598 \\
\hline$\%$ public housing/100 & $-1.420 * * *$ & 0.165 & $1.542^{* * *}$ & 0.138 \\
\hline$\%$ right-wing votes $/ 100$ & 0.116 & 0.127 & $1.073^{* * *}$ & 0.110 \\
\hline First location & $0.984^{* * *}$ & 0.038 & & \\
\hline Moved once $\left(\delta_{1}\right)$ & & & $0.653^{* * *}$ & 0.049 \\
\hline Moved more than once $\left(\delta_{2}\right)$ & & & $0.772^{* * *}$ & 0.068 \\
\hline Baseline hazard function: & & & & \\
\hline$h_{1}$ & $-5.117^{* * *}$ & 0.431 & $-6.018^{* * *}$ & 0.330 \\
\hline$h_{2}$ & $-4.275^{* * *}$ & 0.430 & $-5.987^{* * *}$ & 0.335 \\
\hline$h_{3}$ & $-4.422^{* * *}$ & 0.430 & $-6.184^{* * *}$ & 0.343 \\
\hline$h_{4}$ & $-4.172^{* * *}$ & 0.433 & $-6.205^{* * *}$ & 0.355 \\
\hline$h_{5}$ & $-4.529 * * *$ & 0.434 & $-6.120^{* * *}$ & 0.359 \\
\hline$h_{6}$ & $-4.799 * * *$ & 0.442 & $-6.377^{* * *}$ & 0.370 \\
\hline
\end{tabular}

\begin{tabular}{|l|ll|}
\hline \hline Mixing distribution: & Mean & Std. error \\
\hline$v_{r}^{2}$ & $-4.777^{* * *}$ & 0.239 \\
$v_{u}^{2}$ & $-1.227^{* * *}$ & 0.065 \\
p1 $\left(v_{u}^{1}=0, v_{r}^{1}=0\right)$ & 0.000 & 0.140 \\
p2 $\left(v_{u}^{1}=0, v_{r}^{2}\right)$ & $0.568^{* * *}$ & 0.028 \\
p3 $\left(v_{u}^{2}, v_{r}^{1}=0\right)$ & $0.427^{* * *}$ & 0.024 \\
p4 $\left(v_{u}^{2}, v_{r}^{2}\right)$ & $0.005^{* * *}$ & 0.001 \\
\hline Log likelihood & $-105,317$ & \\
Number of cases & 89,585 & \\
Number of observations & 21,015 & \\
\hline
\end{tabular}


Note 1: One, two and three asterisks indicate significance of the estimate at 10,5 , and $1 \%$ levels, respectively.

Note 2: We also controlled for whether or not the variables 'children 0-2 years', 'children 3-17 years', 'lagged education', and '\% of ethnic group residing in munic.' had missing values.

Note 3: Reference group with respect to origin: Iran.

Note 4: Reference group with respect to immigration year: 1990.

Note 5: Reference group with respect to municipality size: Large municipalities.

\subsection{Non-employment spells}

The estimated hazard function for first transition from non-employment to employment for an individual with mean values of observed characteristics and favourable unobserved characteristics is plotted in Figure 6.1. It is seen that the estimated hazard function exhibits slightly positive duration dependence during the first three years and later mainly negative duration dependence, i.e. the probability of finding employment is increasing with the time spent as non-employed during the first three years and then decreasing. However, none of the estimates for the baseline hazard intervals are significantly different from each other. The duration dependence result does not confirm the hypothesis that refugee immigrants become more employable over time due to time-varying unobservables such as improved host-country language proficiency and increased knowledge about the host-country labour market over time. The most likely explanation is that the effect of increased employability is counteracted by the effects of depreciation of human capital acquired prior to immigration and stigma over time as non-employed. 
Figure 6.1

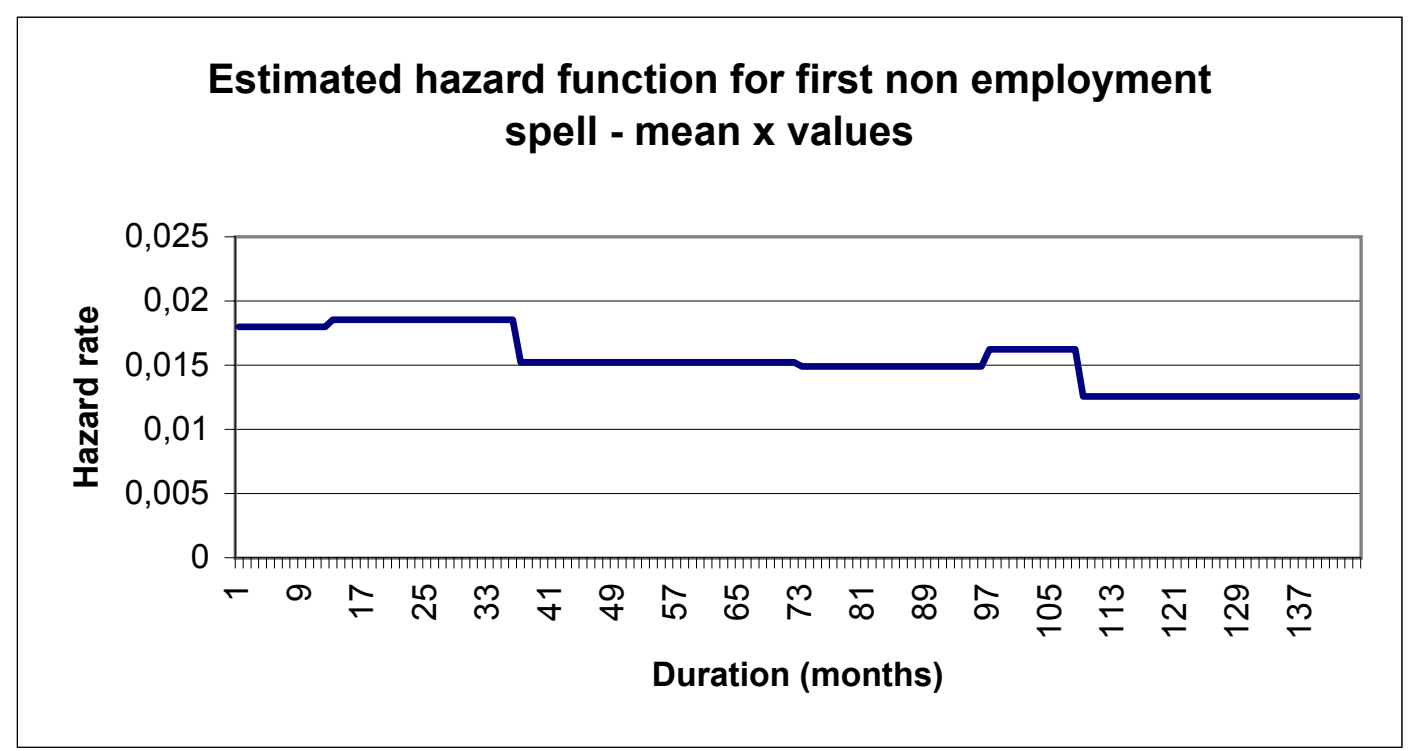




\subsubsection{Effects of location characteristics}

Estimates of the effects of various location of residence characteristics on the hazard rate of first transition for employment, reported in column 4 in Table 6.1 , show the following.

Firstly, the regional unemployment rate has a significantly negative and rather large effect on the hazard rate of exit to first job; a percentage point increase in the regional unemployment rate is connected with a $2.6 \%$ decrease in the job finding hazard rate, the interpretation being that a relatively high regional unemployment rate implies a relatively low job offer arrival rate, all other things equal. The effect of the percentage of county jobs in the municipality of residence is not significantly different from zero. Hence, we do not find support for the hypothesis that residence close to jobs affects the job finding rate via a decreased reservation wage due to low costs of commuting. In contrast, the percentage of right-wing votes at the latest local election does have a significantly positive, although moderate, effect on the job finding hazard rate. Specifically, a percentage point increase in percentage of right-wing votes implies an increase in the job finding hazard rate of $1 \%$. This finding could be due to right-wing dominated municipalities having more efficient active labour market programmes for refugees due to a higher participation of un-employed refugees in private job training rather than class room training as a result of more co-operation with local firms compared to left-wing dominated municipalities.

Secondly, we find a moderate, but significantly positive effect of ethnic concentration on the hazard rate to employment. A precentage point increase in the ethnic concentration increases the hazard rate by $1.2 \%$. This finding can be interpreted as evidence in favour of the hypothesis that ethnic networks enhance the employment opportunities by conveying information about employment opportunities or because jobs are created within ethnic enclaves. However, in view of the theoretical model by Damm and Rosholm (2003) at least part of the effect may arise because an ethnic network locally increases place utility which decreases the reservation wage with respect to local job offers. The reasons for this positive correlation warrant further research.

In contrast, a percentage point increase in immigrants in percentage of the local population decreases the hazard rate into first job by $4.9 \%$. This is an interesting result which may be interpreted as empirical evidence in favour of dispersal policies for refugees. A likely explanation may be that presence of 
immigrants increases the probability of entry into the informal rather than the formal labour market. Another explanation could be congestion; too many immigrants in one place may be more than the local labour market can absorb due to excess supply of low-skilled labour. However, further research into the causes of this negative correlation is needed.

Thirdly, the hazard rate to employment is decreasing in the size of municipality of residence. Specifically, the hazard rate for individuals with residence in a small municipality is more than twice as large than the hazard rate for similar individuals residing in a large municipality while the effect of residence in a medium municipality is also large but somewhat lower than the effect of residence in a small municipality. The interpretation of the effects of size of the local population is not straightforward. It could be an exposure effect, i.e. the smaller the local population the more exposed the refugee is to Danish culture and language. In any case, this finding and the estimate of the effect of presence of immigrants both support the assumption underlying dispersal policies, that geographical dispersal of refugee immigrants away from the larger cities with large existing immigrant populations facilitates their labour market integration. Note, however, that residence in the Greater Copenhagen area versus residence outside that area, does not affect the hazard rate significantly controlling for the other observed location characteristics.

Fourthly, the effect of the number of institutions for vocational and higher educations is significant and positive.

Finally, presence of public housing, which is included in the model to capture the local housing offer arrival rate, turns out to have a small but significantly positive effect on the hazard rate to employment.

\subsubsection{Effects of background characteristics of the individual}

Column 4 in Table 6.1 also shows the estimated effects of demographic and socio-economic characteristics on the hazard rate of first exit to employment.

The hazard rate into employment is seen to be decreasing in age from age 18 (the maximum of the quadratic function in age). It is consistent with the findings of many studies that young adults find (and lose) jobs faster than older adults. The number of infants and children are seen to have highly significant, negative effects on the hazard rate. The negative effect of the number of children is somewhat unexpected, since the effect is found to be positive for men in general labour market studies - an effect that is usually 
explained by the provider role of men being more important in families with children. However, the effect could be due to the relatively high social welfare benefits for uninsured, unemployed couples with children combined with the eligibility rules of receiving social welfare in Denmark in the period 19861998. If one of the spouses got a job, the other spouse would be uneligible for social welfare due to unemployment making it economic rational for a spouse in such a household to accept high-wage jobs only. This economic disincentive problem has been termed the social welfare trap. Rosholm et al. (2000) find a similar result in a different setting.

Being married and a change in marital status have no significant effect on the hazard rate.

Country of origin, however, has rather large significant effects on the hazard rate. Compared to the reference group of individuals from Iran, all ethnic groups except refugees without citizenship experience higher hazard rates, ceteris paribus. Individuals from Ex-Yugoslavia and other parts of Eastern Europe as well as individuals from Chile and Sri Lanka experience the highest hazard rates, all other characteristics being equal. The effects of country of origin are quite large. For instance, the hazard rate for an individual from Sri Lanka is three times as high the hazard rate for an Iranian $(\exp (1.121) \approx 3.07)$. The country of origin indicator variables are meant to capture the effect of cultural and linguistic differences of importance for the labour market integration in the host country.

The effects of the year of immigration indicator variables are interesting. They show that refugees who immigrated to Denmark in the mid-eighties had significantly higher hazard rates of employment than refugees who immigrated later, with two exceptions: refugees who immigrated in 1991-1992 also had significantly higher hazard rates of employment than in the reference year 1990. This finding supports the hypothesis in Rosholm et al. (2000) that low-skilled immigrants' employment opportunities have worsened in Scandinavia since the mid-eighties due to organizational changes.

The larger the ethnic stock in Denmark, the higher is the hazard rate of employment. This finding suggests that ethnic networks have genuine employment effects and that ethnic networks exist across regions in the host country, not only within the municipality of residence.

The effect of number of years of Danish education lagged one year was positive but insignificant at a $10 \%$ significance level, probably due to numerous missing values for that variable. The effect of the log taxable income lagged one year is significantly positive. This effect may capture some unob- 
served abilities of the individuals.

\subsubsection{Effects of geographical mobility}

The total effect of a relocation on the first transition from non-employment to employment is measured as the sum of two effects: an effect due to differences in observed characteristics of the municipality of destination and those of the former municipality of residence and an effect which captures unobserved factors, the average of which is given by the parameter estimates of $\delta_{1}$ and $\delta_{2}$ for the indicator variables 'moved once' and 'moved more than once', respectively, in Table 6.1.

First, concerning the relocation effect due to observables, the average relocation effects due to observed differences in characteristics between the municipality of destination and those of the first municipality of residence have been calculated in the following way,

$$
\operatorname{Exp}\left[\left(\bar{X}_{\text {before }}^{\text {location }}-\bar{X}_{\text {after }}^{\text {location }}\right) \wedge \beta_{u}^{\text {location }}\right]
$$

where $\bar{X}^{\text {location }}$ denotes the mean of observed municipality characteristics across individuals, 'before' refers to the time just before the first relocation took place, and 'after' refers to the time right after the relocation in question had occurred.

Table 6.2 reports the multiplicative effects of differences in the mean of observed characteristics of municipality of residence after first and second relocation, respectively, compared to the mean of observed characteristics of the municipality of placement prior to the relocations, on the hazard rate of first exit to employment.

Table 6.2 The effect of the difference in mean municipality characteristics after relocation compared to before on the hazard rate of first exit to employment.

\begin{tabular}{lll}
\hline \hline \multirow{2}{*}{ Relocation } & $\left(\bar{X}_{\text {before }}^{\text {location }}-\bar{X}_{\text {after }}^{\text {location }}\right) \wedge \beta_{u}^{\text {location }}$ & \\
\hline First & -0.1177 & Multiplicative effect \\
Second & -0.1545 & 0.89 \\
\hline \hline
\end{tabular}

We see that on average the effect of relocation due to observed differences in municipality characteristics was negative, giving rise to multiplicative effects of 0.89 and 0.86 on the hazard rate of exit to first job for first relocation 
and second relocation (relative to no relocation), respectively. Hence, on average refugee migrants moved to locations with less favourable observed characteristics in terms of employment prospects than those of the municipality of placement.

However, the average effect of relocations due to unobservables on the hazard rate of first transition into employment more than counteract the negative effects of relocation due to observables. The estimated average effect of relocations, $\delta_{1}$ and $\delta_{2}$, are presented in Table 6.1, Part B. Both are significantly positive and large at a $1 \%$ significance level. By taking the exponential value of $\delta$, we get the multiplicative effect of the average effect of relocation on the hazard rate of first transition into employment. That is, the multiplicative effect of carrying out a relocation from the municipality of placement is 1.92 whereas the multiplicative effect of having moved twice is even higher, 2.16. ${ }^{10}$ These positive effects of carrying out a cross-municipal move are likely to stem at least in part from unobserved differences in characteristics of the former municipality of residence and the new municipality of residence, such as presence of an ethnic network in the municipality of destination which can facilitate their job search in the new local labour market. Not only may these unobserved factors affect the job offer arrival rate directly, they may also contribute to lower the reservation wage (and thus increase the offer acceptance rate). Since we only observe when an individual begins in a job and not - which would have been preferable - when an individual actually got the job, the effects may in part arise because some of the movers actually have found a job in another region prior to moving to the region; i.e. there may be reverse causality. This problem is addressed in Section 7. In short, we find no evidence of reverse causality.

The total average effect of relocations on the employment hazard is calculated either as the exponential of the sum of the two estimated effects or as the product of the two multiplicative effects of relocation due to observed and unobserved factors, respectively, which amounts to 1.70 for one move and to 1.85 for at least two moves. Hence, on average first-time movers increase the hazard rate of exit to employment by $70 \%$ and twice movers by $85 \%$, which are substantial effects.

The size of the estimated effects may become clearer if the effects are

\footnotetext{
${ }^{10}$ The multiplicative effect of carrying out a second move due to unobserved factors is given by the exponential value of the difference between $\delta_{2}$ and $\delta_{1}$, which amounts to 1.13.
} 
specified in terms of the change in predicted mean duration of first nonemployment spell. The predicted mean duration of first non-employment spell for a person with observed characteristics $\mathrm{X}$ and unobserved characteristics $\hat{v}_{u}$ is given by

$$
E\left(T_{u} \mid X, \hat{v}_{u}\right)=\int_{0}^{\infty} \hat{S}\left(t_{u} \mid X, \hat{v}_{u}\right) d t_{u}=\int_{0}^{\infty}\left(\exp \left(-\int_{0}^{t_{u}} \hat{h}\left(s \mid X, \hat{v}_{u}\right) d s\right) d t_{u}\right.
$$

Figures 6.2 and 6.3 show the predicted hazard rates for exit to first job for two individuals with close to average observed characteristics, but one has favourable and the other unfavourable unobserved labour market characteristics. ${ }^{11}$ The three curves differ by residential mobility only; one depicts the hazard rate into employment of an individual who is never mobile, the second of one who moves once after 21 months, and the third depicts the hazard rate of someone moving twice after 21 and 42 months. It is seen that the first move really increases the hazard rate into employment, while subsequent moves have little additional effect.

Figures 6.4 and 6.5 show the predicted survival rates for the same individuals.

\footnotetext{
${ }^{11}$ The individuals have the following observed characteristics: They are 32 years old, married, have one child older than 2 years of age, are refugees from Lebanon without citizenship who immigrated in 1986 , have a total ethnic stock of 8,800 persons, have missing value for years of Danish education and have an annual taxable income of DKK 29,900. They live in a municipality with the following characteristics: medium-sized, outside the Greater Copenhagen area, immigrants constitute $6.4 \%$ of the local population, $6.7 \%$ of their ethnic group in Denmark live here, the regional unemployment rate is $10 \%, 32 \%$ of the county jobs are here, it has 11 educational institutions, public housing constitutes $23 \%$ of the housing stock, and finally $40 \%$ of the votes at the latest local election went to right-wing political parties.
} 
Figure 6.2

Estimated employment hazard rate for an individual with close to average observed characteristics and favourable unobserved characteristics

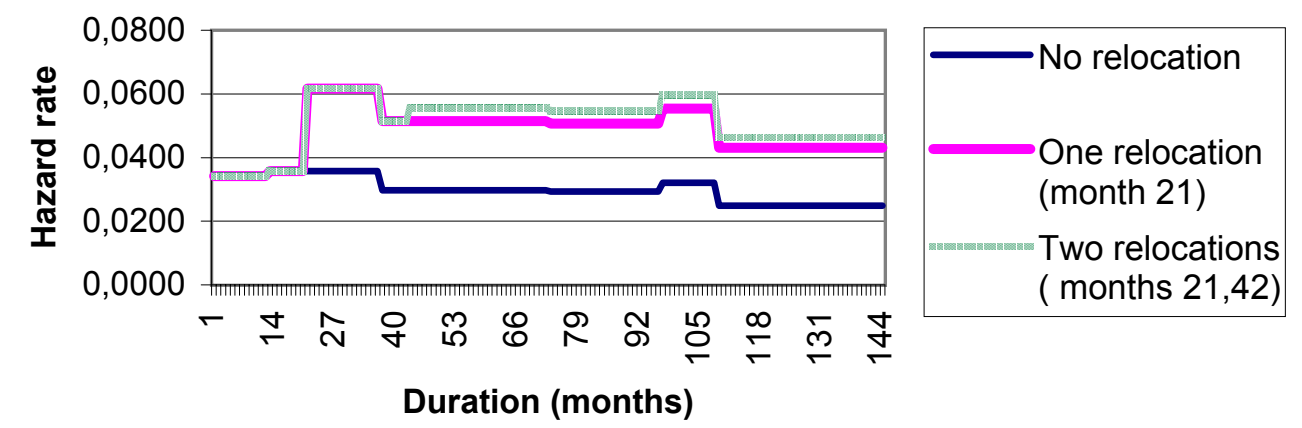

Figure 6.3

Estimated employment hazard rate for an individual with close to average observed characteristics and unfavourable unobserved characteristics
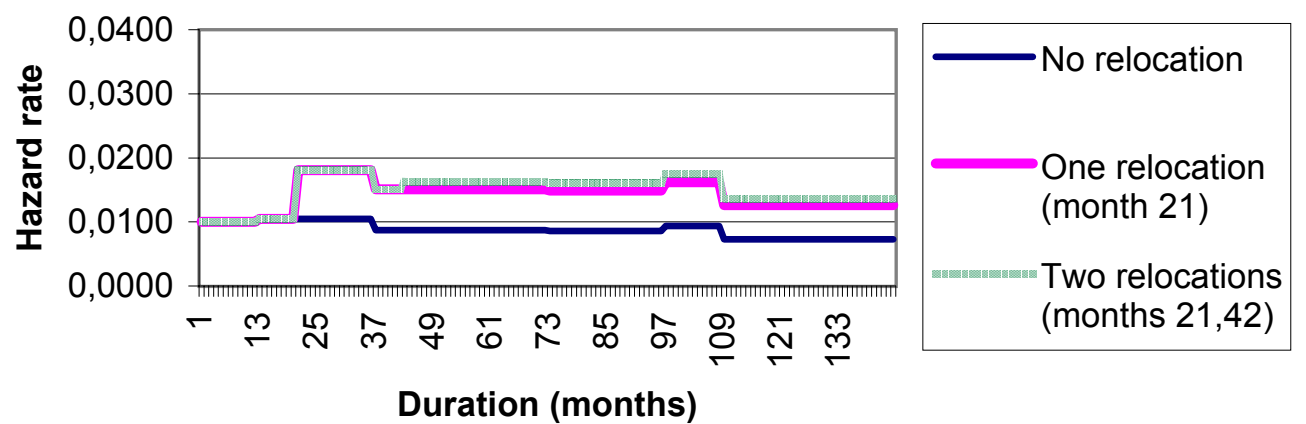

Duration (months) 
Figure 6.4

Predicted mean probability of survival of first nonemployment spell until time $t$ for an individual with close to average characteristics and favourable unobserved characteristcs

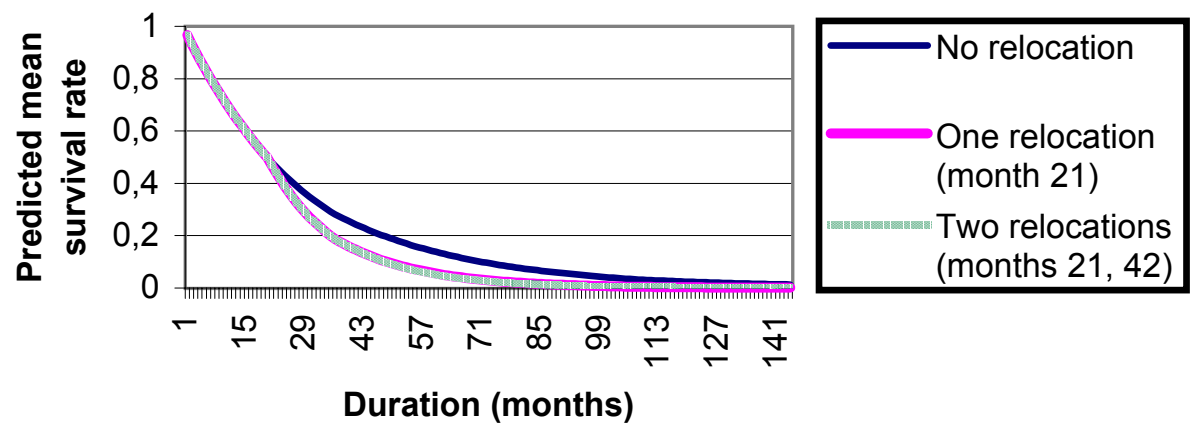

Figure 6.5

Predicted mean probability of survival of first nonemployment spell until time $t$ for an individual with close to average characteristics and unfavourable unobserved characteristics

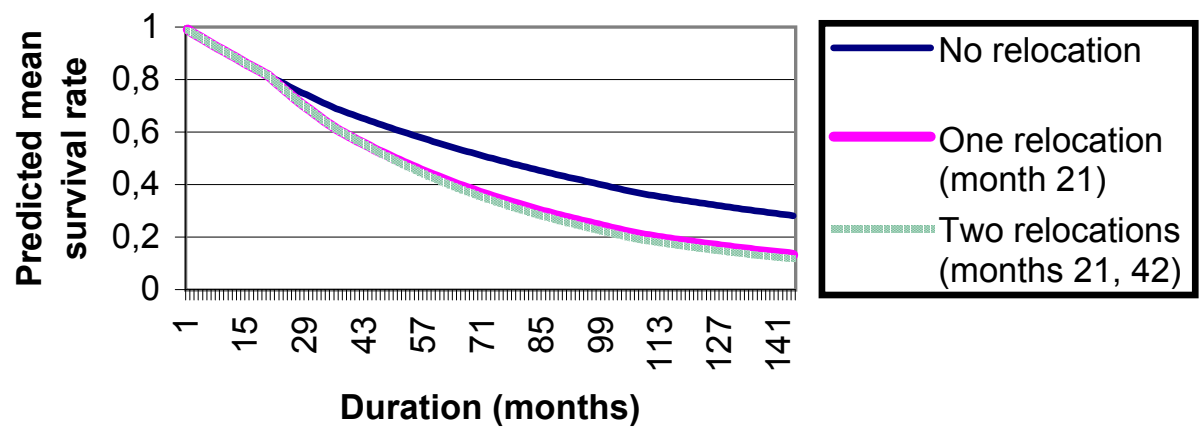


Table 6.3 summarizes the estimated relocation effects in terms of change in predicted mean duration of first non-employment spell for these individuals by stating the predicted mean duration of first non-employment spell for the individual in each of the following three cases: zero relocations, one relocation carried out 20 months after initial settlement and two relocations of which the first relocation is carried out in month 21 and the second in month 42 after initial settlement. ${ }^{12}$

Table 6.3 Predicted mean duration of first non-employment spell for an individual with close to mean characteristics (months).

\begin{tabular}{l|lll}
\hline \hline $\begin{array}{l}\text { Number of relocations } \\
\text { Unobs. heterogeneity of }\end{array}$ & None & $\begin{array}{l}\text { One } \\
(\text { month 21) }\end{array}$ & $\begin{array}{l}\text { Two } \\
\text { (months 21 and 42) }\end{array}$ \\
\hline Type 1 $\left(\exp \left(\hat{v}_{u}\right)=1\right)$ & 29.7 & 22.8 & 22.5 \\
Type 2 $\left(\exp \left(\hat{v}_{u}\right)=0.29\right)$ & 113.3 & 72.5 & 69.2 \\
'Average' person & 65.8 & 44.3 & 42.7 \\
\hline \hline
\end{tabular}

Note: An 'average' person is $0.568 \cdot$ type $1+0.432 \cdot$ type 2 .

It is seen that the relocation effects correspond to a decrease in the predicted mean duration of first non-employment spell for an individual with close to mean characteristics of 7-41 months for one relocation and of 7-44 months for at least two relocations, depending on the unobserved ability type. For an 'average' person, the effect of residential mobility is close to 22 months. Thus, on average both relocations away from the municipality of placement and further relocations helped jobless refugee immigrants getting into their first job considerably faster than they would have if they had stayed in the municipality of placement, even if mobility takes place after some time. This result supports the hypothesis that refugees moved for job search reasons, that is, to improve employment prospects.

Turning to the observed effect of relocation (that is, the change in the hazard caused by the change in $x$ 's) on the hazard rate at the individual level, we get a more diversified story. The multiplicative observed effects at the individual level of first and second relocation are plotted in Figures 6.6 and 6.7 .

\footnotetext{
${ }^{12}$ The predicted mean durations in Table 6.3 are calculated using an observation period of 480 months, i.e. 40 years.
} 
Figure 6.6

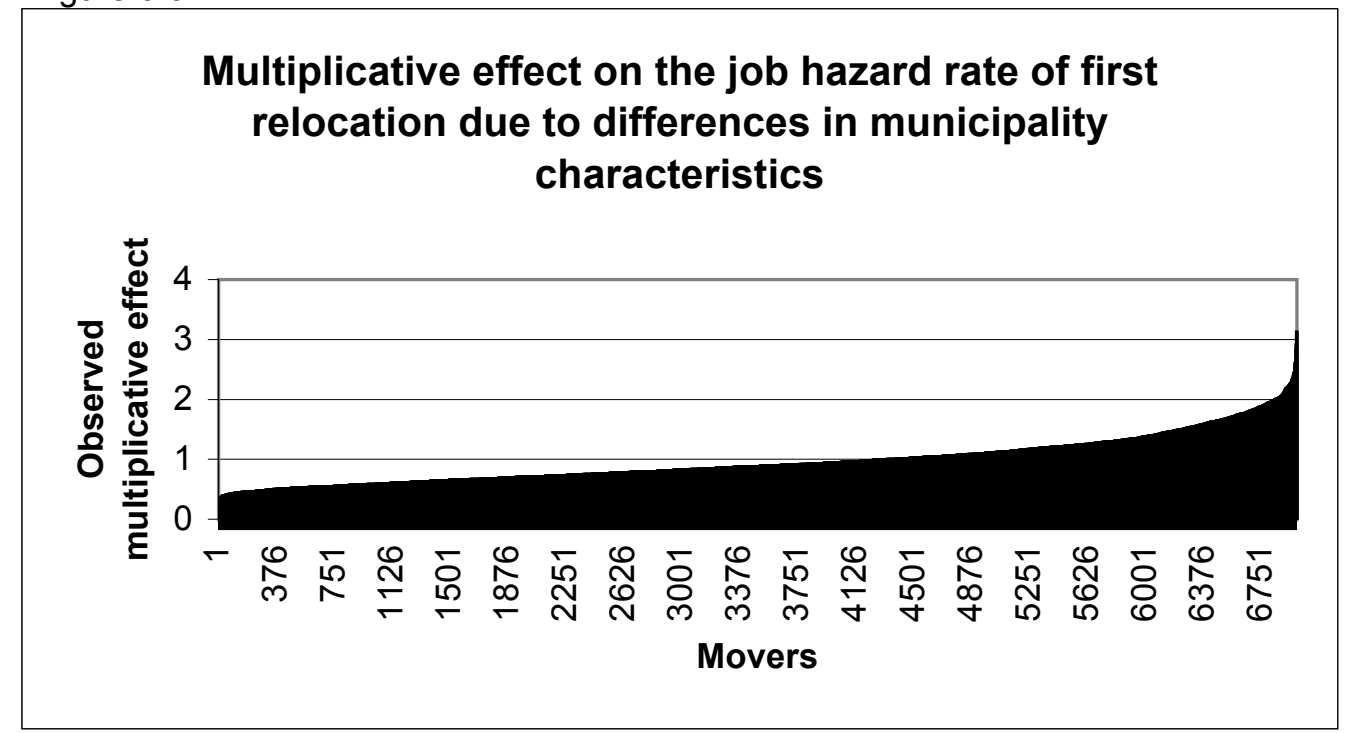

Figure 6.7

Multiplicative effect on the job hazard rate of second relocation due to differences in municipality characteristics

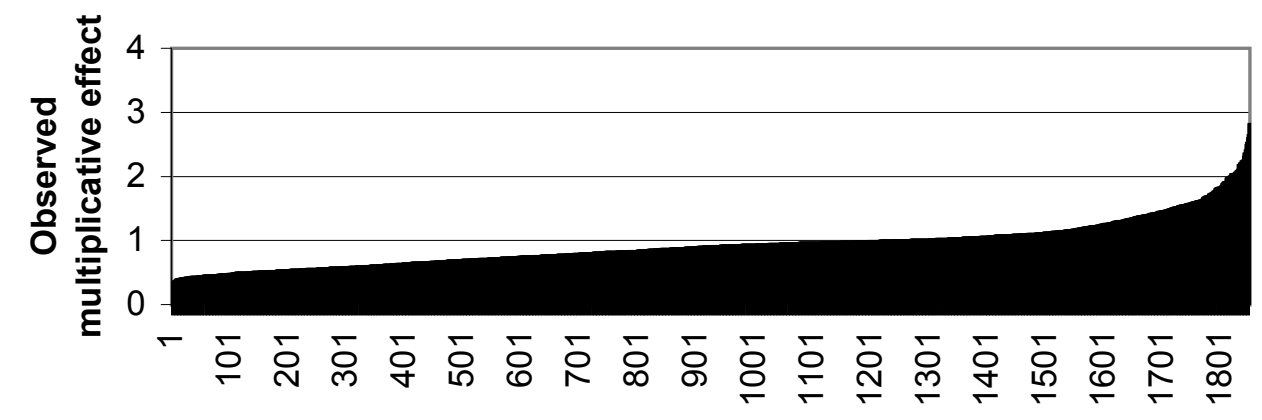

Twice movers 
The observed relocation effect on the job hazard rate is positive for only $37 \%$ of first-time movers and for $31 \%$ of second-time movers, giving rise to a multiplicative effect of $\Delta \bar{X}^{\text {location }} \beta_{u}$ location on the job hazard rate greater than 1 for these individuals. This implies that approximately one third of first and second-time relocations experienced an increase in the job hazard rate for 'observable reasons'. Note however that the relocation effect due to unobserved factors for each individual is unknown.

\subsection{Selection and unobserved heterogeneity}

The estimated hazard function for non-employed individuals' transition to another municipality of residence is plotted in Figure 6.8. The estimated hazard function is seen to exhibit positive duration dependence during the first two years after settlement in a given municipality and decreasing duration dependence thereafter. The result is likely to be an analog of Jovanovich's matching model in which employees and employers gradually learn about the match quality. In the present context, refugees are likely to spend some time collecting and evaluating information about the region of residence to learn about match quality. In addition, initially the housing offer arrival rate is likely to be very low due to lack of knowledge of the housing market in the host country and due to lack of savings and a personal network needed for access to housing outside the public housing sector. The highest peak of the hazard function occurs in the interval 19-24 months after settlement. This may be due to the fact that some of the individuals who wanted to move to another municipality waited until the end of participation in the introduction programme which in general lasted for 18 months. 
Figure 6.8

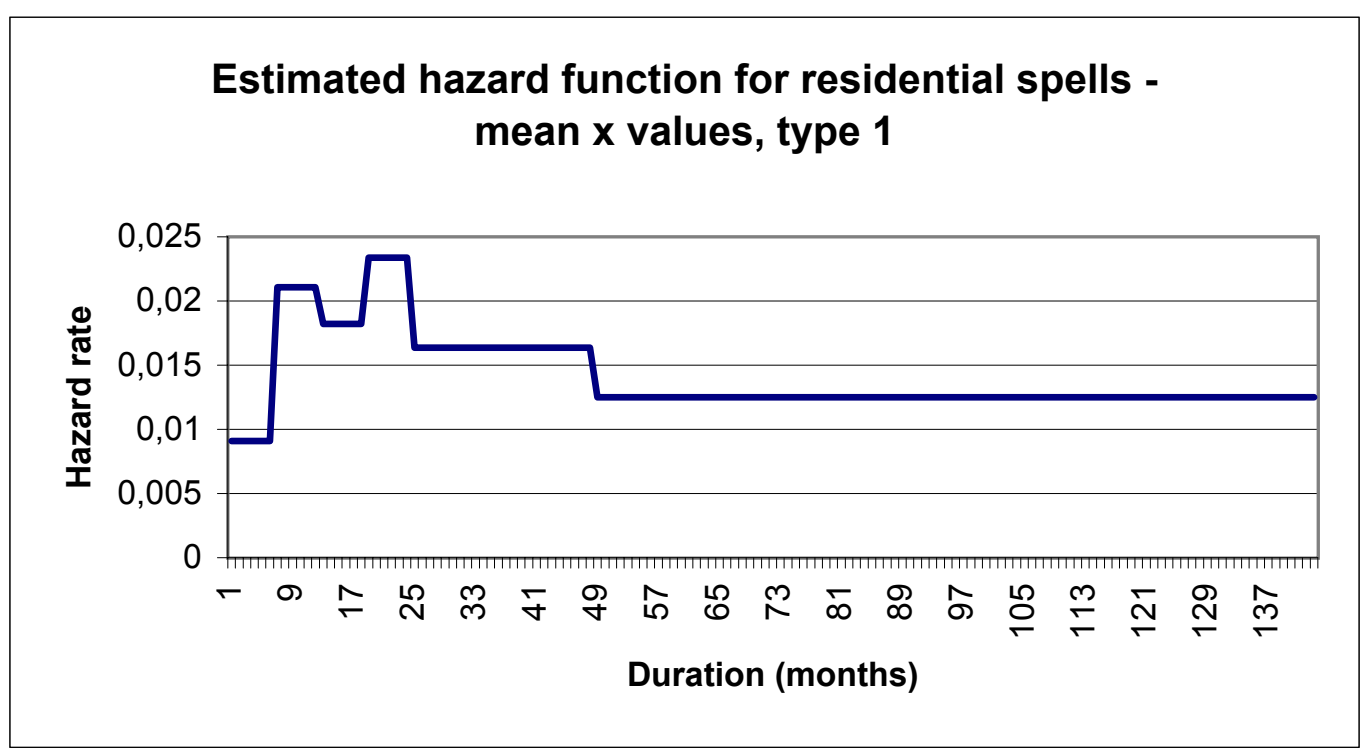


Residence in the first municipality of residence, the municipality of assignment, implies a relocation hazard rate which is as much as $168 \%(\exp [0.984] \approx$ 2.68) higher than the hazard rate for relocation out of later municipalities of residence. This could be expected given the initial random assignment of most of the individuals to a municipality of residence.

The estimated effects of demographic and socio-economic characteristics on the relocation hazard rate are reported in column 2 in Table 6.1. Remember that most of the demographic characteristics were included both as controls for differences in initial settlement between refugee groups due to the dispersal policy and to capture genuine differences in migration propensitity between refugee groups.

Marriage and number of infants and children are seen to have significantly negative effects on the relocation hazard rate, while change in marital status has a significantly positive effect. The interpretations of these findings are the following. First, the more family an individual has (spouse and children), the more ties to the local environment the household has. The psychological costs of relocation are therefore higher than for a single individual. Second, concerning the positive effect on the geographical mobility hazard rate of a change in marital status the interpretation is that the forming or the dissolution of a marriage is likely to lead to an adjustment of housing consumption in form of a larger or smaller residence which may imply a cross-municipal border move. The effect of age is insignificant.

Country of origin has large effects on the relocation hazard rate. The hazard rate is significantly higher for refugees from Iraq and Somalia than for individuals belonging to the reference group Iran, whereas individuals from Rumania, Sri Lanka and Vietnam have significantly lower hazard rates than Iranians. So all other characteristics being equal, some refugee immigrant groups expect higher benefits and/or lower costs from relocation than other groups. ${ }^{13}$ The net benefits of relocation to a municipality with relatively many fellow countrymen are likely to be larger for refugee immigrants whose cultural, social and economic environment in the country of origin differs considerably from such environments in the host country than for refugee immigrants whose cultural, social and economic background is similar to that of the majority group. The former group has more consumption characteristics unique to their ethnic group and their ethnic group initially has a more

\footnotetext{
${ }^{13}$ Note however, that the initial location was found to be affected be ethnicity in Damm (2003a).
} 
limited information about the cultural, social and economic environment in the host country.

The size of the ethnic stock has a significant negative effect on the hazard rate of migration. A likely interpretation is that it is not only the concentration of fellow countrymen which matters for refugees' place utility but also the size of the ethnic network. At least part of the effect may instead be explained by the finding in Damm (2003a) that refugees with a large stock of fellow countrymen in Denmark at the time of immigration, ceteris paribus, were more likely to live in a larger municipality initially than refugees with a small stock of fellow countrymen initially.

Overall, the hazard rate of migration is increasing in the year of immigration, which reflects that refugees who arrived in the second half of the dispersal policy period were more dispersed across municipalities, including the small municipalities, than refugees who arrived in the first half of the policy period.

Turning to the effects of socioeconomic characteristics, an additional year of Danish education lagged has a modest, but significantly positive effect on the relocation hazard rate. A likely interpretation of the result is that better educated individuals have lower costs of and higher returns from migration. ${ }^{14}$ The level of annual pre-tax income in the previous year has an insignificant effect on the migration rate.

The estimated effects of location characteristics are also reported in column 2, Table 6.1. The estimated effects are, except for one important variable, as expected, cf. Section 3. First, note that ethnic concentration and $\%$ of immigrants have significantly negative effects on the hazard rate of migration. These findings are consistent with the hypothesis that place utility is increasing in these two factors which capture the importance of ethnic networks and ethnic goods. Furthermore, the hazard rate of migration is, as expected, significantly higher for individuals residing in medium and small rather than large municipalities but somewhat surprisingly also higher for individuals residing in the Greater Copenhagen area compared to individuals outside that area. From the study by Damm (2003b), we know that migrants placed in small municipalities tend to migrate to medium-sized and large municipalities which confirms the hypothesis that refugees prefer larger, urban

\footnotetext{
${ }^{14}$ From a related study by Damm (2003b), we know that the effect of an additional year of Danish education is to increase the hazard rate of out-migration from the municipality of placement to medium-sized municipalities.
} 
areas to smaller urban and rural districts. Descriptive evidence from the present study shows that moves out of a county in the Greater Copenhagen area constitute $19 \%$ of first-time moves across county borders; however, $73 \%$ of these moves are moves within the Greater Copenhagen area. Turning to second-time moves across county borders, $48 \%$ of such moves are moves out of a county in the Greater Copenhagen area of which cross-county moves within the Greater Copenhagen area constitute $68 \%$. Hence, the finding of relatively high migration hazard rates for refugees who live in the Greater Copenhagen area is mainly explained by high rates of migration within that area.

Further, the percentage of public housing out of the total municipality housing stock has a significantly negative effect on the relocation hazard rate. This is consistent with the theoretical prediction according to which the local housing offer arrival rate influences the rate of out-migration negatively.

The regional unemployment rate which is closely related to the job offer arrival rate is, unexpectedly, also found to have a significantly negative and numerically large effect on the relocation hazard rate. However, the result is consistent with the macro result found in a gross migration study for Denmark that the higher the regional unemployment rate relative to the unemployment rate for other regions, the lower is the migration rate (DillingHansen and Smith 1996). Considering the significant importance of a low unemployment rate for refugees' employment probability, the result of a negative effect of the regional unemployment rate on the relocation hazard rate is unfortunate.

To understand the result found for regional unemployment better, note that in the related study by Damm (2003b) on push factors for placed refugees, a high regional unemployment rate in the municipality of placement was found to imply a high hazard rate of out-migration to large municipalities which in the period of observation on average had even higher regional unemployment rates than small and medium-sized municipalities. Hence, high regional unemployment was found to be a push factor in the first migration decision, but low regional unemployment did not appear to be a pull factor. And if it is not a pull factor in the first migration decision, then why should it be a push factor in later migration decisions?

Interestingly, the effect of the share of right-wing votes at the latest local election is insignificant. Hence, whatever right-wing dominated municipalities do that increases the hazard rate into employment of refugees in the municipality, there is no evidence in this study that it makes refugees 'flee' 
the municipality (nor is there any evidence as to the contrary).

Finally, the estimation results support the hypothesis that access to institutions for vocational or higher education is an important determinant of refugees' place utility. One additional local institution for vocational and higher education decreases the hazard rate of migration by $2 \%$. The effect of the share of the county job in the municipality of residence is found to be insignificant.

Turning to the estimation of unobserved heterogeneity, two mass points different from zero are identified and the estimated probabilities of three of the four possible combinations of unobserved heterogeneity are significantly different from zero at a $1 \%$ significance level. In consequence, the parameter estimates reported in Table 6.1 should not be subject to bias due to selective mobility, because we have controlled for it.

\section{Sensitivity analysis and discussion}

We do not control for host-country language proficiency, abilities, motivation, education obtained in and work experience from the country of origin in the estimation of effects of location-specific characteristics on the job and relocation hazard rates, because currently we do not have access to such information. Furthermore, we are unable to control for whether or not a person needed special psychological or medical treatment upon immigration, which may have had some influence on the initial municipality of residence. However, we believe that the consequences of these lacks are mitigated by allowing for unobserved heterogeneity in both equations.

More seriously, the large average effect of migration on the hazard rate to employment may not be a genuine effect of migration. Part of the effect may stem from reverse causality, because we do not observe the month in which an individual gets a job but only the month in which he starts working. If a considerable share of refugees who find employment in the observation period find employment outside their local labour market and therefore subsequently migrate, the estimated causal effect of migration will be overestimated. We have investigated the importance of this potential problem by allowing the causal effect of relocation to change with time since mobility. If the sequence is such that you first find a job, then move and then start in the job (that is, if there is reverse causality), we would expect the observed hazard rate into employment to be very high immediately after relocation and to decline 
thereafter.

The estimation results are reported in Table A.4 in the Appendix. The effects of the first move and of more than one move are estimated for 6 different intervals of time since the move: 1-3 months, $4-6$ months, 7-12 months, 1318 months, 19-24 months and more than 24 months. Both relocation effects are estimated to increase over time since the move. Furthermore, the first effect is estimated to be quite small 1-3 months after the move and is only significant at a $10 \%$ significance level. We, therefore, do not find evidence that part of the large effect of mobility is due to reverse causality.

Another relevant criticism of the econometric analysis is that the 'noanticipation' requirement for identification of the mobility effect may not be satisfied in the present context; individuals may be too good at anticipating the time of mobility for the requirement to be satisfied. In that case, individuals who anticipate to migrate in the near future may lower their job search locally prior to migrating which also leads to overestimation of the estimated effect of migration on the hazard rate into employment. The validity of this assumption was discussed in Section 5, and we do not believe that the violation of the assumption is so severe as to invalidate our results, given that anticipation of the exact date of mobility will generally not be known more than a couple of months in advance.

We have investigated the robustness of the result that the relocation hazard rate is decreasing in regional unemployment by substituting that measure of unemployment with the unemployment rate for semi-skilled insured workers in the municipality of residence and in the county of residence in turns. Refugees are found to be less sensitive to the rate of unemployment for semiskilled workers in the municipality of residence than the overall regional unemployment rate; a percentage point increase in the rate of unemployment for semi-skilled workers increases the hazard rate to employment by $2 \%$ and, as before, decreases the hazard rate of migration by $0.7 \%$. There are only small changes in the effects of other observed characteristics of the municipality of residence on the hazard rates; however, residence in a medium-sized municipality is found to imply a significantly higher hazard rate of migration than residence in a large municipality. The estimates of the relocation effects due to unobservables are also close to the estimates in the basic model; 0.64 and 0.76 for first and subsequent relocations, respectively. 


\section{Conclusion}

The main aim of this empirical study was to investigate how dispersal policies affect labour market integration of refugee immigrants subject to the policy. We have investigated this by estimation of the effects of location characteristics and the average effect of subsequent migration on the hazard rate of exit to first job for male refugees aged 18-59 who were subject to the Danish Dispersal Policy 1986-1998.

We estimated the effects using a bivariate mixed proportional hazard model specification which allowed us to take potential location sorting into account when estimating the average treatment effect of migration on the hazard rate of exit to first job. Failure to account for the selection into location in the econometric model would have resulted in biased average effects of mobility. The main results are as follows:

First, we find that residence in a small or medium-sized municipality further characterised by low regional unemployment, a small immigrant population, a high concentration of fellow countrymen and a large number of institutions for vocational and higher education increases the hazard rate into the first job substantially for refugees. These results are empirical evidence in favour of the view that dispersal of new refugees away from the larger cities with large existing immigrant populations promotes refugees' labour market integration. However, they also emphasize the importance of dispersal of refugees in big clusters of refugees with the same ethnic origin, across locations with low regional unemployment, and a relatively high number of educational institutions.

We interpret the results on the basis of search models with simultaneous search for job and location of residence. Low regional unemployment increases the job offer arrival rate of refugees. So does residence in small municipalities, probably due to exposure to Danes and/or because case-workers in smaller municipalities are better at matching unemployed refugees with vacant positions in local firms. Presence of fellow countrymen increases place utility and thereby increases reservation place utility. The ethnic concentration result therefore supports the search theoretical result from Damm and Roshom (2003) that high current place utility implies a low local reservation wage. The result that the hazard rate into first job is decreasing in immigrants in per cent of the local population may be explained by refugees in immigrant enclaves being at greater risk of entering the informal rather than the formal labour market. The result merits future research, though. 
Second, on average the employment prospects measured in terms of $o b$ servable characteristics of the municipality of residence deteriorate when nonemployed, initially placed refugees carry out a cross-municipal move. Specifically, the average deterioration of observed municipality characteristics due to moves corresponds to a decrease in the hazard rate to first job of $11 \%$ after first move and $14 \%$ after second move (relative to no move). However, the average effect of cross-municipal moves due to unobservables on the hazard rate into the first job is large and positive and dominates the negative effect of relocation due to deterioration of observable location characteristics. On average, first relocations increase the hazard rate into first job by $92 \%$ due to unobservables. Moreover, on average two relocations compared to no relocation increase the hazard rate by $116 \%$ due to unobservables. The average net effect of cross-municipal moves by non-employed, initially placed refugees amounts to an increase in the hazard rate of exit to first job of $70 \%$ for first relocation and $85 \%$ for two relocations. In terms of the duration until the first job, model simulations showed that first relocations on the average implied that an individual with mean characteristics got his first job 22 months earlier than he would have otherwise. Now, this result is for a person who does not move until 21 months after the initial assignment to a municipality. Needless to say, the effect on the duration until first job would be much larger if immigrants initially were able to choose where they wanted to live and work. ${ }^{15}$

We, therefore, conclude that, in the context of the Danish Dispersal Policy 1986-1998, cross-municipal moves carried out by male refugees placed prior to their first job on average promoted their labour market integration and that this speaks against the use of dispersal policies.

The policy recommendations are that in order not to hurt the speed of labour market integration by carrying out dispersal policies for new refugee immigrants, the authorities in charge of the dispersal should locate individuals in locations offering favourable employment prospects as well as place utility sufficiently high so as to deter relocation. Refugees were found to have favourable employment prospects mainly in small and medium-sized municipalities with low regional unemployment, a large number of educa-

\footnotetext{
${ }^{15}$ In fact, model simulations show that free choice of first residential location for an individual with mean characteristics would decrease time until first job by as much as 29 months. The calculation is based on the assumption that the individual chooses to settle initially in a municipality which has observed and unobserved characteristics equal to the mean characteristics of the destination municipalities of first-time movers.
} 
tional institutions, high concentration of fellow countrymen but few other immigrants. Their mobility was dampened by the presence of fellow countrymen, good access to public housing, high unemployment (unfortunately) and by living in large municipalities.

The results also imply that the introduction of further restrictions on the geographical mobility of placed refugees (such as the 1999 reform) in order

to reduce the relatively high rates of subsequent migration would on average be expected to hamper labour market integration of refugees.

\section{References}

[1] Abbring, J.H. and G.J. van den Berg. 2003. The Non-Parametric Identification of Treatment Effects in Duration Models. Working paper, Free University Amsterdam, Amsterdam. forthcoming in Econometrica.

[2] Abbring, J.H., G.J. van den Berg and J.C. van Ours. 1997. The effect of unemployment insurance sanctions on the transition rate from unemployment to employment. Working Paper, Tinbergen Institute, Amsterdam.

[3] Bartel, A. 1989. Where do the new immigrants live? Journal of Labor Economics, 7(4):371-91.

[4] Bauer, T., G. Epstein and I.N. Gang. 2002. Herd Efects or Migration Networks? The Location Choice of Mexican Immigrants in the U.S, IZA Discussion Paper 551.

[5] Bolvig, I., P. Jensen and M. Rosholm. 2003. The Employment Effects of Active Social Policy in Denmark. Unpublished paper, Department of Economics, Aarhus School of Business and University of Aarhus.

[6] Bonnal, L., D. Fougere and A. Serandon. 1997. Evaluating the impact of French employment policies on individual labour market histories. Review of Economic Studies 64:683-713.

[7] Borjas, G.J. 1999. Immigrants and welfare magnets. Journal of Labor Economics, 17(4):607-637. 
[8] Card, D. and D. Sullivan. 1988. Measuring the effect of subsidized training programs on movements in and out of employment. Econometrica $56: 497-530$.

[9] Chiswick, B.R. and P.W. Miller. 2001. Do Enclaves Matter in Immigrant Adjustment? Working paper, Department of Economics. University of Illinois at Chicago.

[10] Damm, A.P. 2003a. The Danish Dispersal Policy on Refugee Immigrants 1986-1998: A Natural Experiment? Chapter 1 in this thesis.

[11] Damm, A.P. 2003b. Immigrants' Location Preferences: Exploiting a Natural Experiment. Chapter 2 in this thesis.

[12] Damm, A. P. 2003c. Employment Spillover from Ethnic Networks? Chapter 5 in this thesis.

[13] Damm, A. P. and M. Rosholm. 2003. Employment Effects of Dispersal Policies on Refugee Immigrants, Part I: Theory. Chapter 3 in this thesis.

[14] Danish Refugee Council (Dansk Flygtningehjælp). 1993. Om geografisk spredning af asylansøgere, flygtninge og indvandrere. Internal report written by Bente Bondebjerg and Morten Iversen.

[15] Devine, T.J. and M. M. Kiefer. 1993. The Empirical Status of Job Search Theory. Labour Economics, 1: 3-24.

[16] Dilling-Hansen, M. and V. Smith. 1996. Estimating inter-regional migration using a hiring function approach. Working Paper, Department of Economics, Aarhus University.

[17] Djuve, A. B. and H. C. Kavli. 2000. Styring over eget liv. Levekår pg flytteaktivitet blant flyktinger i lys av myndighetenes bosettingsarbeid. Fafo-rapport 344.

[18] Edin, P.-A., P. Fredriksson and O. Åslund. 2001. Settlement policies and the economic success of immigrants. CEPR Discussion Paper 2730.

[19] Gritz, R.M. 1993. The impact of training on the frequency and duration of employment. Journal of Econometrics 57: 21-51. 
[20] Hummelgaard, H., L. Husted, A. Holm, M. Baadsgaard and B. Olrik. 1995. Etniske minoriteter, integration og mobilitet. Copenhagen: AKF.

[21] Jaeger, D.A. 2000. Local Labor Markets, Admission Categories and Immigrant Location Choice. Working Paper, Department of Economics, Hunter College, NY.

[22] Kobrin, F. E. and A. Speare. 1983. Out-migration and ethnic communities. International Migration Review 17: 425-44.

[23] Lancaster, T. 1990. The Econometric Analysis of Transition Data. Cambridge: Cambridge University Press.

[24] Lillard, L.A. 1993. Simultaneous equations for hazards. Journal of Econometrics 56:189-217.

[25] Lillard, L.A. and C.W.A. Panis. 1996. Marital status and mortality: The role of health. Demography 33:313-327.

[26] Ministry of Internal Affairs (Indenrigsministeriet). 1995. Integration af bosniske krigsflygtninge i Danmark. 1. delrapport fra Indenrigsministeriets udvalg vedrørende integration af bosniske krigsflygtninge, flygtninge og indvandrere.

[27] Ministry of Internal Affairs (Indenrigsministeriet). 1996. Udlæ ndinge '96. En talmæssig belysning af udlændinge i Danmark, ch. 6.

[28] Piore, M. J. 1979. Birds of passage: Migrant labor and industrial societies. Cambridge: Cambridge University Press.

[29] Rosholm, M., K. Scott, and L. Husted. 2000. The Times They Are A-Changin'. Organizational change and immigrant employment opportunities in Scandinavia. IZA Discussion Paper 258.

[30] Van den Berg, G.J., B. van der Klauw and J.C. van Ours. 2004. Punitive sanctions and the transition from welfare to work. Forthcoming in Journal of Labor Economics 22.

[31] Van Ommeren, J., P. Rietveld and P. Nijkamp. 1997. Commuting: in search of jobs and residences. Journal of Urban Economics 42:402-421. 
[32] Van Ommeren, J., P. Rietveld and P. Nijkamp. 2000. Job mobility, residential mobility and commuting: A theoretical analysis using search theory. The Annals of Regional Science 34:213-232.

[33] Wolpert, J. 1965. Behavioral Aspects of the Decision to Migrate. Papers of the Regional Science Association, 19:159-169.

[34] Yapa, L., M. Polese and J. Wolpert. 1971. Interdependencies of commuting, migration and job site relocations. Economic Geography 47: 59-72.

[35] Zavodny, M. 1997. Welfare and the locational choices of new immigrants. Federal Reserve Bank of Dallas Economic Review, Second Quarter 1997.

[36] Zavodny, M. 1998. Determinants of Recent Immigrants' Locational Choices. Federal Reserve Bank of Atlanta Working Paper 98-3.

[37] Åslund, O. 2001. Now and forever? Initial and subsequent location choices of immigrants. IFAU Working Paper 11. 


\section{Appendix}

\section{Construction of variables:}

The following variables were constructed based on information from the longitudinal administrative registers of Statistics Denmark on the immigrant population in Denmark 1984-2001.

Years of education. This variable refers to total number of years of education obtained in Denmark. The variable was constructed using information about an individual's highest completed education obtained in Denmark from the registers which have extremely detailed education information; for educations lasting more than a year, information is given both on the education and the highest year of the education completed. Furthermore, the level of the education can be inferred from the education code, because in general the educational level is increasing in the code value. The codes therefore allow us to construct a variable of years of education completed which takes values 0.5 years (for pre-school class) to 17 years (for masters degrees).

$\log$ (income). This income variable refers to annual gross income of the individual, i.e. the sum of all taxable income of the individual, including income transfers.

Ethnic stock. The total number of immigrants from each of the 17 refugee countries was obtained for every year 1986-1997. The 'ethnic stock' variable denotes the total number of immigrants from the refugee's country of origin.

Ethnic concentration. This variable is constructed as a refugee's number of fellow countrymen in the municipality of residence in per cent of the total number of immigrants from that country of origin.

$\%$ immigrants. The variable is calculated as the total number of immigrants residing in the municipality in per cent of the total number of municipality inhabitants.

Greater Copenhagen. This indicator variable takes the value 1 if a refugee lives in Copenhagen and Frederiksberg County Municipality or in Copenhagen County and 0 otherwise.

The following variables have been constructed using the annual time-series data on municipality characteristics from Statistics Denmark's website.

Small municipality. This indicator variable takes the value 1 if a refugee lives in a municipality with less than or equal to 10,000 inhabitants, of which there were approximately 139 out of the total of 275 Danish municipalities. 
Medium municipality. This indicator variable takes the value 1 if a refugee lives in a municipality with more than 10,000 and less than or equal to 100,000 inhabitants. This includes approximately 132 Danish municipalities.

Large municipality. This indicator variable takes the value 1 if a refugee lives in a municipality with more than 100,000 inhabitants. Only four Danish municipalities fall into this category: Copenhagen, Aarhus, Odense and Aalborg.

$\%$ of county jobs. The variable gives the number of individuals employed in the municipality of residence in per cent of the total number of individuals employed in the county. Administratively and politically, Denmark is divided into 14 counties and one so-called county municipality.

\# educational institutions. This variable includes 40 different types of institutions for vocational and higher education and denotes the number of such institutions in the municipality of residence.

$\%$ public housing. The variable denotes the number of public housing dwellings for all-year residence in the municipality of residence in per cent of the total number of dwellings for all-year around residence in the municipality of residence.

$\%$ right-wing votes. This variable is constructed as the sum of votes for the Liberal Party and the Conservative People's Party in per cent of the sum of votes for the Liberal Party, the Conservative People's Party, the Socialdemocratic Party and the Socialist People's Party at the latest local election. The two former parties are traditional right-wing parties whereas the latter two are traditional left-wing parties. Local elections take place every four years.

Regional unemployment rate. This variable has been constructed by the Local Government Studies on information from the Ministry of Transport on the costs of transportation from the largest post office in each municipality to each of the other 274 largest post offices in the other municipalities. The regional unemployment rate used in the present study gives the unemployment rate in a radius of DKK 60 of transport around the largest post office in the municipality of residence. DKK 60 correspond to approximately USD 9.20. The information on unemployment stems from Statistics Denmark's $10 \%$ administrative register sample of the Danish population 1984-2001. 
Table A.1. Summary statistics (initial values). Mean (std. dev.) Part A.

\begin{tabular}{|l|lll|l|}
\hline \hline Group of individuals & $\begin{array}{l}\text { Stayers } \\
\text { Variables }\end{array}$ & $\begin{array}{l}\text { Movers once } \\
\mathrm{N}=14,037)\end{array}$ & $\begin{array}{l}\text { Movers more than once } \\
(\mathrm{N}=5,129)\end{array}$ & $\begin{array}{l}\text { All } \\
(\mathrm{N}=2,849)\end{array}$ \\
\hline Age & $30.99(9.44)$ & $29.49(8.36)$ & $26.92(6.89)$ & $30.27(0.07)$ \\
Married & $0.56(0.50)$ & $0.50(0.50)$ & $0.36(0.48)$ & $0.53(0.50)$ \\
\# children 0-2 years & $0.19(0.46)$ & $0.22(0.49)$ & $0.16(0.44)$ & $0.04(0.20)$ \\
\# children 3-17 years & $0.67(1.17)$ & $0.61(1.20)$ & $0.39(1.05)$ & $0.20(0.47)$ \\
Origin: & & & & $0.63(1.17)$ \\
Poland & $0.02(0.14)$ & $0.01(0.12)$ & $0.01(0.12)$ & \\
Iraq & $0.11(0.31)$ & $0.16(0.37)$ & $0.17(0.38)$ & $0.02(0.13)$ \\
Iran & $0.12(0.32)$ & $0.17(0.38)$ & $0.26(0.44)$ & $0.13(0.33)$ \\
Vietnam & $0.06(0.23)$ & $0.03(0.17)$ & $0.03(0.16)$ & $0.14(0.35)$ \\
Sri Lanka & $0.13(0.33)$ & $0.09(0.29)$ & $0.05(0.22)$ & $0.05(0.21)$ \\
No citizenship & $0.16(0.36)$ & $0.22(0.42)$ & $0.31(0.46)$ & $0.11(0.36)$ \\
Ethiopia & $0.01(0.12)$ & $0.01(0.11)$ & $0.008(0.09)$ & $0.19(0.39)$ \\
Afghanistan & $0.01(0.12)$ & $0.02(0.14)$ & $0.01(0.12)$ & $0.02(0.13)$ \\
Somalia & $0.08(0.27)$ & $0.11(0.32)$ & $0.12(0.33)$ & $0.02(0.13)$ \\
Rumania & $0.01(0.11)$ & $0.007(0.08)$ & $0.005(0.07)$ & $0.09(0.29)$ \\
Chile & $0.002(0.04)$ & $0.001(0.04)$ & $0(0)$ & $0.01(0.1)$ \\
Bosnia-Herzegovina & $0.27(0.44)$ & $0.14(0.35)$ & $0.02(0.13)$ & $0.002(0.04)$ \\
Croatia & $0.003(0.06)$ & $0.002(0.05)$ & $0(0)$ & $0.22(0.41)$ \\
Macedonia & $0.003(0.05)$ & $0.002(0.04)$ & $0(0)$ & $0.003(0.05)$ \\
Slovenia & $0.0004(0.02)$ & $0.0002(0.01)$ & $0(0)$ & $0.002(0.05)$ \\
Former Yugoslavia & $0.02(0.14)$ & $0.01(0.09)$ & $0.002(0.05)$ & $0.0003(0.02)$ \\
\hline
\end{tabular}


Table A.1. Summary statistics (initial values). Mean (std. dev.). Part B.

\begin{tabular}{|l|lll|l|}
\hline \hline $\begin{array}{l}\text { Group of individuals } \\
\text { Variables }\end{array}$ & $\begin{array}{l}\text { Stayers } \\
(\mathrm{N}=14,037)\end{array}$ & $\begin{array}{l}\text { Movers once } \\
(\mathrm{N}=5,129)\end{array}$ & $\begin{array}{l}\text { Mover more than once } \\
(\mathrm{N}=1,849)\end{array}$ & $\begin{array}{l}\text { All } \\
(\mathrm{N}=21,015)\end{array}$ \\
\hline Ethnic stock & $8,451(5,341)$ & $6,897(4,718)$ & $5,114(3,247)$ & $7,779(5,151)$ \\
Year of immigration: & & & & \\
1985 & $0.03(0.18)$ & $0.05(0.22)$ & $0.07(0.05)$ & $0.04(0.20)$ \\
1986 & $0.17(0.38)$ & $0.18(0.39)$ & $0.26(0.44)$ & $0.18(0.39)$ \\
1987 & $0.07(0.25)$ & $0.08(0.27)$ & $0.12(0.33)$ & $0.07(0.26)$ \\
1988 & $0.05(0.22)$ & $0.08(0.27)$ & $0.13(0.33)$ & $0.07(0.25)$ \\
1989 & $0.07(0.25)$ & $0.08(0.27)$ & $0.12(0.33)$ & $0.07(0.26)$ \\
1990 & $0.04(0.20)$ & $0.06(0.23)$ & $0.07(0.25)$ & $0.05(0.21)$ \\
1991 & $0.05(0.22)$ & $0.07(0.26)$ & $0.08(0.27)$ & $0.06(0.24)$ \\
1992 & $0.07(0.25)$ & $0.08(0.27)$ & $0.05(0.22)$ & $0.07(0.26)$ \\
1993 & $0.05(0.23)$ & $0.08(0.26)$ & $0.05(0.22)$ & $0.06(0.24)$ \\
1994 & $0.05(0.22)$ & $0.04(0.20)$ & $0.02(0.13)$ & $0.05(0.21)$ \\
1995 & $0.34(0.47)$ & $0.20(0.40)$ & $0.03(0.17)$ & $0.28(0.45)$ \\
Municip. of residence: & & & & \\
Greater Copenhagen & $0.16(0.37)$ & $0.18(0.38)$ & $0.20(0.40)$ & $0.17(0.38)$ \\
Medium municipality & $0.58(0.49)$ & $0.62(0.48)$ & $0.61(0.49)$ & $0.59(0.49)$ \\
Small municipality & $0.10(0.29)$ & $0.20(0.40)$ & $0.17(0.37)$ & $0.13(0.33)$ \\
\% immigrants & $5.23(3.55)$ & $4.43(3.04)$ & $4.52(3.11)$ & $4.97(3.41)$ \\
\% fellow countrymen & $0.39(0.44)$ & $0.34(0.52)$ & $0.24(0.31)$ & $0.37(0.45)$ \\
Ethnic concentration & $5.26(7.50)$ & $3.49(6.56)$ & $3.97(6.05)$ & $4.71(7.21)$ \\
Regional unempl. rate & $9.74(2.27)$ & $9.79(2.39)$ & $9.41(2.35)$ & $9.72(2.31)$ \\
\% of county jobs & $26.62(26.12)$ & $19.05(23.97)$ & $23.11(27.43)$ & $24.47(25.94)$ \\
\# educ. institutions & $9.46(10.18)$ & $6.31(9.09)$ & $7.67(10.39)$ & $8.53(10.04)$ \\
\% public housing & $21.15(10.68)$ & $17.68(10.81)$ & $18.31(10.72)$ & $20.05(10.83)$ \\
\% right-wing votes & $40.90(12.27)$ & $43.92(14.05)$ & $41.82(12.95)$ & $41.72(12.85)$ \\
\hline \hline
\end{tabular}

Note: Standard deviations are reported in parentheses. 
Table A.2 Geographical distribution of refugees in our sample across counties. Per cent.

\begin{tabular}{|c|c|c|c|c|c|}
\hline Region & County & Population in 1993 & Immigrants & Initial distr. of refugees & Final distr. of refugees \\
\hline \multirow[t]{7}{*}{ Zealand: } & Copenhagen and & & & & \\
\hline & Frederiksberg munic. & 10.68 & 11.61 & 10.84 & 16.58 \\
\hline & Copenhagen & 11.66 & 7.97 & 6.14 & 8.73 \\
\hline & Frederiksborg & 6.68 & 5.95 & 5.36 & 4.68 \\
\hline & Roskilde & 4.27 & 4.66 & 2.9 & 2.81 \\
\hline & West Zealand & 5.53 & 3.35 & 5.96 & 4.64 \\
\hline & Storstroem & 4.96 & 2.64 & 6.07 & 4.47 \\
\hline \multirow[t]{2}{*}{ Other islands: } & Bornholm & 0.87 & 1.70 & 0.49 & 0.45 \\
\hline & Funen & 8.98 & 3.77 & 10.43 & 10.47 \\
\hline \multirow[t]{7}{*}{ Jutland: } & Southern Jutland & 4.85 & 4.13 & 4.70 & 3.64 \\
\hline & Ribe & 4.26 & 2.79 & 5.56 & 4.47 \\
\hline & Vejle & 6.45 & 2.93 & 7.76 & 6.88 \\
\hline & Ringkoebing & 5.19 & 2.34 & 4.55 & 4.32 \\
\hline & Aarhus & 11.77 & 4.46 & 12.55 & 14.53 \\
\hline & Viborg & 4.44 & 1.70 & 5.47 & 4.00 \\
\hline & Northern Jutland & 9.40 & 2.34 & 11.23 & 9.23 \\
\hline All & & 100.00 & 4.88 & 100.00 & 100.00 \\
\hline
\end{tabular}


Table A.3 Geographical distribution of subgroups of refugees across counties. Per cent.

\begin{tabular}{|c|c|c|c|c|c|}
\hline \multirow[b]{2}{*}{ Region } & \multirow[b]{2}{*}{ County } & \multicolumn{2}{|c|}{$\begin{array}{l}\text { Initial distribution } \\
\text { Non-employment spell }\end{array}$} & \multicolumn{2}{|c|}{$\begin{array}{l}\text { Final distribution } \\
\text { Non-employment spell }\end{array}$} \\
\hline & & Completed & Right-censored & Completed & Right-censored \\
\hline \multirow[t]{7}{*}{ Zealand: } & Copenhagen and & & & & \\
\hline & Frederiksberg munic. & 8.60 & 13.28 & 11.11 & 22.74 \\
\hline & Copenhagen & 5.62 & 6.71 & 8.24 & 9.25 \\
\hline & Frederiksborg & 5.29 & 5.44 & 4.94 & 4.41 \\
\hline & Roskilde & 2.88 & 2.92 & 3.14 & 2.45 \\
\hline & West Zealand & 6.07 & 5.84 & 4.95 & 4.31 \\
\hline & Storstroem & 5.54 & 6.64 & 3.99 & 4.99 \\
\hline \multirow[t]{2}{*}{ Other islands: } & Bornholm & 0.52 & 0.46 & 0.50 & 0.40 \\
\hline & Funen & 9.18 & 11.78 & 9.18 & 11.88 \\
\hline \multirow[t]{7}{*}{ Jutland: } & Southern Jutland & 4.60 & 4.80 & 3.88 & 3.37 \\
\hline & Ribe & 7.18 & 3.81 & 6.46 & 2.30 \\
\hline & Vejle & 8.49 & 6.96 & 7.61 & 6.07 \\
\hline & Ringkoebing & 6.38 & 2.56 & 6.62 & 1.82 \\
\hline & Aarhus & 12.93 & 12.14 & 15.07 & 13.95 \\
\hline & Viborg & 5.27 & 5.68 & 4.26 & 3.71 \\
\hline & Northern Jutland & 11.44 & 10.99 & 10.04 & 8.35 \\
\hline All & & 100.00 & 100.00 & 100.00 & 100.00 \\
\hline
\end{tabular}


Table A.4 Estimates from a bivariate MPH model with time-varying treatment effects. Part A.

\begin{tabular}{|l|ll|ll|}
\hline \hline & Relocation & & Employment \\
\cline { 2 - 5 } Variables & Estimate & Std. err. & Estimate & Std. err. \\
\hline Age/100 & 1.396 & 1.134 & $2.897^{* * *}$ & 0.961 \\
Married squared & $-3.700^{* *}$ & 1.607 & $-9.268^{* * *}$ & 1.363 \\
Marital status change & $-0.062^{*}$ & 0.032 & -0.010 & 0.027 \\
\# children 0-2 years/10 & $-1.228^{* * * *}$ & 0.046 & -0.076 & 0.048 \\
\# children 3-17 years/10 & $-0.914^{* * *}$ & 0.275 & $-2.803^{* * *}$ & 0.223 \\
Poland & -0.058 & 0.113 & $-0.614^{* * *}$ & 0.108 \\
Iraq & $0.123^{*}$ & 0.066 & $0.379^{* * *}$ & 0.076 \\
Vietnam & $-0.640^{* * *}$ & 0.079 & $0.477^{* * *}$ & 0.060 \\
Sri Lanka & $-0.637^{* * *}$ & 0.063 & $1.121^{* * *}$ & 0.059 \\
No citizenship & 0.037 & 0.041 & $0.096^{* *}$ & 0.049 \\
Ethiopia & 0.159 & 0.149 & $0.394^{* * *}$ & 0.131 \\
Afghanistan & $0.238^{*}$ & 0.127 & $0.598^{* * *}$ & 0.123 \\
Somalia & $0.253^{* * *}$ & 0.080 & $0.434^{* * *}$ & 0.071 \\
Rumania & $-0.533^{* * *}$ & 0.161 & $1.505^{* * *}$ & 0.112 \\
Chile & -0.675 & 0.492 & $1.180^{* * *}$ & 0.243 \\
Bosnia-Herzegovina & -0.075 & 0.098 & $1.032^{* * *}$ & 0.080 \\
Ex-Yugoslavia (not BH) & -0.290 & 0.351 & $2.113^{* * *}$ & 0.171 \\
Former Yugoslavia & -0.071 & 0.210 & $0.948^{* * *}$ & 0.108 \\
Ethnic stock/10 & $-0.153^{* *}$ & 0.077 & $0.350^{* * *}$ & 0.075 \\
Years of educ. lagged/10 & $0.689^{* *}$ & 0.289 & 0.194 & 0.209 \\
log(income) lagged/10 & -0.054 & 0.034 & $0.245^{* * *}$ & 0.028 \\
Immigrat. year: 1985 & 0.020 & 0.082 & $0.196^{* * *}$ & 0.076 \\
Immigrat. year: 1986 & 0.025 & 0.067 & $0.172^{* * *}$ & 0.062 \\
Immigrat. year: 1987 & -0.041 & 0.070 & $0.112^{*}$ & 0.065 \\
Immigrat. year: 1988 & -0.004 & 0.068 & 0.022 & 0.064 \\
Immigrat. year: 1989 & -0.004 & 0.067 & -0.035 & 0.062 \\
Immigrat. year: 1991 & 0.100 & 0.068 & 0.053 & 0.066 \\
\hline
\end{tabular}


Table A.4 Estimates from a bivariate MPH model with time-varying treatment effects. Part B.

\begin{tabular}{|c|c|c|c|c|}
\hline & \multicolumn{2}{|l|}{ Relocation } & \multicolumn{2}{|c|}{ Employment } \\
\hline Variables & Estimate & Std. err. & Estimate & Std. err. \\
\hline Immigrat. year: 1992 & 0.105 & 0.073 & $0.139^{* *}$ & 0.067 \\
\hline Immigrat. year: 1993 & $0.206^{* * *}$ & 0.077 & -0.070 & 0.074 \\
\hline Immigrat. year: 1994 & 0.090 & 0.089 & -0.075 & 0.084 \\
\hline Immigrat. year: 1995 & $0.642^{* * *}$ & 0.100 & $-0.214^{* *}$ & 0.090 \\
\hline Greater Copenhagen & $0.636^{* * *}$ & 0.048 & -0.019 & 0.042 \\
\hline Medium municipality & $0.237^{* * *}$ & 0.081 & $0.599^{* * *}$ & 0.059 \\
\hline Small municipality & $0.637^{* * *}$ & 0.098 & $0.872^{* * *}$ & 0.077 \\
\hline$\%$ immigrants $/ 100$ & $-3.415^{* * *}$ & 0.771 & $-5.333^{* * *}$ & 0.606 \\
\hline Ethnic concentration/10 & $-0.325^{* * *}$ & 0.034 & $0.124^{* * *}$ & 0.027 \\
\hline Reg. unemp. rate/100 & $-3.434^{* * *}$ & 0.657 & $-3.397 * * *$ & 0.556 \\
\hline$\%$ of county jobs $/ 100$ & 0.160 & 0.249 & -0.002 & 0.192 \\
\hline \# educ. institutions/100 & $-1.240^{*}$ & 0.765 & $1.793^{* * *}$ & 0.601 \\
\hline$\%$ public housing/100 & $-1.566^{* * *}$ & 0.165 & $1.596^{* * *}$ & 0.138 \\
\hline$\%$ right-wing votes $/ 100$ & 0.064 & 0.128 & $1.053^{* * *}$ & 0.110 \\
\hline First location & $0.928^{* * *}$ & 0.039 & & \\
\hline Moved once $\delta_{1 \_} 1$ & & & $0.179^{*}$ & 0.094 \\
\hline Moved once $\delta_{1 \_}{ }^{-} 2$ & & & $0.475^{* * *}$ & 0.084 \\
\hline Moved once $\delta_{1}{ }^{-} 3$ & & & $0.530^{* * *}$ & 0.065 \\
\hline Moved once $\delta_{1 \_}^{-} 4$ & & & $0.553^{* * *}$ & 0.069 \\
\hline Moved once $\delta_{1 \_}{ }^{-}$ & & & $0.534^{* * *}$ & 0.076 \\
\hline Moved once $\delta_{1 \_}{ }^{-} 6$ & & & $0.561^{* * *}$ & 0.051 \\
\hline Moved more than once $\delta_{2}{ }_{1}$ & & & $0.416^{* * *}$ & 0.160 \\
\hline Moved more than once $\delta_{2 \_}{ }^{-}$ & & & $0.516^{* * *}$ & 0.157 \\
\hline Moved more than once $\delta_{2} 3$ & & & $0.521 * * *$ & 0.120 \\
\hline Moved more than once $\delta_{2}{ }^{-}{ }_{4}$ & & & $0.641^{* * *}$ & 0.117 \\
\hline Moved more than once $\delta_{2}{ }^{-} 5$ & & & $0.504^{* * *}$ & 0.504 \\
\hline Moved more than once $\delta_{2 \_} 6$ & & & $0.786^{* * *}$ & 0.786 \\
\hline
\end{tabular}


Table A.4 Estimates from a bivariate MPH model with time-varying treatment effects. Part C.

\begin{tabular}{|l|ll|ll|}
\hline & Relocation & & Employment & \\
\hline$h_{1}$ & Estimate & Std. error & Estimate & Std. error \\
$h_{2}$ & $-4.977^{* * *}$ & 0.435 & $-5.800^{* * *}$ & 0.338 \\
$h_{3}$ & $-4.127^{* * *}$ & 0.435 & $-5.749^{* * *}$ & 0.343 \\
$h_{4}$ & $-4.256^{* * *}$ & 0.436 & $-5.934^{* * *}$ & 0.351 \\
$h_{5}$ & $-4.000^{* * *}$ & 0.438 & $-5.964^{* * *}$ & 0.363 \\
$h_{6}$ & $-4.372^{* * *}$ & 0.440 & $-5.873^{* * *}$ & 0.367 \\
\hline
\end{tabular}

\begin{tabular}{|l|ll|}
\hline Mixing distribution: & Estimate & Std. error \\
\hline$v_{r}^{2}$ & $-4.474^{* * *}$ & 0.191 \\
$v_{u}^{2}$ & $-1.117^{* * *}$ & 0.066 \\
p1 $\left(v_{u}^{1}=0, v_{r}^{1}=0\right)$ & 0.000 & 0.241 \\
p2 $\left(v_{u}^{1}=0, v_{r}^{2}\right)$ & $0.519^{* * *}$ & 0.025 \\
p3 $\left(v_{u}^{2}, v_{r}^{1}=0\right)$ & $0.476^{* * *}$ & 0.024 \\
p4 $\left(v_{u}^{2}, v_{r}^{2}\right)$ & $0.005^{* * *}$ & 0.001 \\
\hline Log likelihood & $-105,500$ & \\
Number of cases & 120,915 & \\
Number of observations & 21,015 & \\
\hline
\end{tabular}

Note 1: One, two and three asterisks indicate significance of the estimate at 10,5 , and $1 \%$ levels, respectively.

Note 2: Also controlled for whether or not the variables 'children 0-2 years', 'children 3-17 years', 'lagged education' and '\% of ethnic group residing in munic.' had missing values.

Note 3: Reference group with respect to origin: Iran.

Note 4: Reference group with respect to immigration year: 1990.

Note 5: Reference group with respect to municipality size: Large municipalities.

Note 6: $\delta_{m \_}, m=1,2$ denotes the treatment effect 1-3 months after move $m, \delta_{m \_} 2$ denotes the treatment effect $4-6$ months after move $m, \delta_{m \_3}$ denotes the treatment effect 7-12 months after move $m, \delta_{m \_} 4$ denotes the treatment effect 13-18 months after move $m, \delta_{m_{-} 5}$ denotes the treatment effect 19-24 months after move $m, \delta_{m \_} 6$, denotes the treatment effect more than 24 months after move $m$. 


\section{IZA Discussion Papers}

\begin{tabular}{|c|c|c|c|c|}
\hline No. & Author(s) & Title & Area & Date \\
\hline 911 & J. Wagner & $\begin{array}{l}\text { Are Nascent Entrepreneurs Jacks-of-all-Trades? } \\
\text { A Test of Lazear's Theory of Entrepreneurship } \\
\text { with German Data }\end{array}$ & 5 & $10 / 03$ \\
\hline 912 & $\begin{array}{l}\text { D. Checchi } \\
\text { A. Filippin }\end{array}$ & An Experimental Study of the POUM Hypothesis & 1 & $10 / 03$ \\
\hline 913 & $\begin{array}{l}\text { S. Pivnenko } \\
\text { D. DeVoretz }\end{array}$ & $\begin{array}{l}\text { The Recent Economic Performance of Ukrainian } \\
\text { Immigrants in Canada and the U.S. }\end{array}$ & 1 & $10 / 03$ \\
\hline 914 & $\begin{array}{l}\text { A. R. Cardoso } \\
\text { P. Portugal }\end{array}$ & $\begin{array}{l}\text { Bargained Wages, Wage Drift and the Design of } \\
\text { the Wage Setting System }\end{array}$ & 5 & $10 / 03$ \\
\hline 915 & $\begin{array}{l}\text { R. Hujer } \\
\text { C. Zeiss }\end{array}$ & $\begin{array}{l}\text { Macroeconomic Impacts of ALMP on the } \\
\text { Matching Process in West Germany }\end{array}$ & 6 & $10 / 03$ \\
\hline 916 & $\begin{array}{l}\text { S. C. Wolter } \\
\text { S. Mühlemann } \\
\text { J. Schweri }\end{array}$ & $\begin{array}{l}\text { Why Some Firms Train Apprentices and Many } \\
\text { Others Do Not }\end{array}$ & 5 & $10 / 03$ \\
\hline 917 & $\begin{array}{l}\text { R. Euwals } \\
\text { H. Roodenburg }\end{array}$ & $\begin{array}{l}\text { A Note on the Redistributive Effect of } \\
\text { Immigration }\end{array}$ & 1 & $10 / 03$ \\
\hline 918 & $\begin{array}{l}\text { V. Jakobsen } \\
\text { M. Rosholm }\end{array}$ & $\begin{array}{l}\text { Dropping out of School? A Competing Risks } \\
\text { Analysis of Young Immigrants' Progress in the } \\
\text { Educational System }\end{array}$ & 1 & $10 / 03$ \\
\hline 919 & M. Fertig & $\begin{array}{l}\text { The Impact of Economic Integration on } \\
\text { Employment - An Assessment in the Context of } \\
\text { EU Enlargement }\end{array}$ & 2 & $10 / 03$ \\
\hline 920 & $\begin{array}{l}\text { Ø. A. Nilsen } \\
\text { K. G. Salvanes } \\
\text { F. Schiantarelli }\end{array}$ & $\begin{array}{l}\text { Employment Changes, the Structure of } \\
\text { Adjustment Costs, and Plant Size }\end{array}$ & 1 & $11 / 03$ \\
\hline 921 & $\begin{array}{l}\text { P. Egger } \\
\text { M. Pfaffermayr } \\
\text { A. Weber }\end{array}$ & $\begin{array}{l}\text { Sectoral Adjustment of Employment: The Impact } \\
\text { of Outsourcing and Trade at the Micro Level }\end{array}$ & 2 & $11 / 03$ \\
\hline 922 & $\begin{array}{l}\text { J. Merz } \\
\text { D. Burgert }\end{array}$ & $\begin{array}{l}\text { Working Hour Arrangements and Working Hours } \\
\text { - A Microeconometric Analysis Based on } \\
\text { German Time Use Diary Data }\end{array}$ & 5 & $11 / 03$ \\
\hline 923 & $\begin{array}{l}\text { U. Dulleck } \\
\text { P. Frijters } \\
\text { R. Winter-Ebmer }\end{array}$ & $\begin{array}{l}\text { Reducing Start-Up Costs for New Firms: The } \\
\text { Double Dividend on the Labour Market }\end{array}$ & 5 & $11 / 03$ \\
\hline 924 & $\begin{array}{l}\text { A. P. Damm } \\
\text { M. Rosholm }\end{array}$ & $\begin{array}{l}\text { Employment Effects of Dispersal Policies on } \\
\text { Refugee Immigrants, Part I: Theory }\end{array}$ & 1 & $11 / 03$ \\
\hline 925 & $\begin{array}{l}\text { A. P. Damm } \\
\text { M. Rosholm }\end{array}$ & $\begin{array}{l}\text { Employment Effects of Dispersal Policies on } \\
\text { Refugee Immigrants, Part II: Empirical Evidence }\end{array}$ & 1 & $11 / 03$ \\
\hline
\end{tabular}

An updated list of IZA Discussion Papers is available on the center's homepage www.iza.org. 